\title{
Ethnomedicinal applications of animal species by the local communities of Punjab, Pakistan
}

\author{
Muhammad Altaf ${ }^{1}$, Muhammad Umair ${ }^{2}$, Abdul Rauf Abbasi ${ }^{3}$, Noor Muhammad ${ }^{4}$ and Arshad Mehmood Abbasi ${ }^{5^{*}}$ (D)
}

\begin{abstract}
Background: Different species of animals are being utilized in traditional therapies by various cultures for a long time and such uses still exist in folk medicine. The present study aimed to document animal-based traditional therapies used by the local communities of Jhelum and Lahore districts of the Punjab province, Pakistan.

Methods: Field surveys were conducted in 2015-2016 in six different sites of the study areas. Data were collected through semi-structured interviews and face to face conversation with local informants.

Results: The ethnomedicinal uses of 57 species of animals including mammals, birds, fish, reptiles, amphibian, and invertebrates $(30,25,25,7,3.5$, and $3.5 \%$, respectively) were documented. Meat, oil, brain, fats, milk, eggs, and skin were the most utilized body parts. Ovis orientalis punjabiensis, Francolinus francolinus, Sperata sarwari, Channa punctata, Oreochromis niloticus, Ctenopharyngodon idella, Cyprinus carpio, Labeo rohita, and Carassius auratus were reported for the first time to treat human diseases, i.e., allergy, epilepsy, fever, joint pain, and backache, to act as aphrodisiac, and to enhance memory. Streptopelia decaocto and S. tranquebarica were the most frequently utilized species with highest frequency of citation (32 for each). Columba livia depicted highest fidelity level and used value of $92.86 \%$ and 0.89 , respectively.
\end{abstract}

Conclusions: Being agro-pastoralists, the inhabitants of Jhelum possess more traditional knowledge compared to Lahore. The present study could be important for conservation and sustainable use of animal biodiversity in this region. Additionally, detailed study on chemical profiling and bioactivities may lead to animal-based novel drug discovery.

Keywords: Animal species, Traditional therapies, Local communities, Pakistan

\section{Background}

Different body parts of wild and domestic animals are being utilized since ancient time in the prevention and protection of human health disorders [1] and such therapeutics are termed as zootherapy [2]. Zootherapy has profound history with wide geographical distribution. It has been reported that Chinese used earthworms to treat diseases nearly 4000 years ago [3]. Over, 1500 animal species have been documented in Traditional Chinese Medicines, which are used to treat various diseases [4]. Around $15-20 \%$ of the Ayurvedic medicines is of

\footnotetext{
*Correspondence: arshad799@yahoo.com

${ }^{5}$ Department of Environment Sciences, COMSATS University Islamabad,

Abbottabad Campus, Abbottabad, Pakistan

Full list of author information is available at the end of the article
}

animals' origin [5], and more than 500 species of invertebrates are used to cure both common and complex illnesses in India [6].

Petting, watching, stroking, and working with different animal species can be relaxing, can lower heart beat and stroke, and can be physically beneficial [7]. Chemicals from animals and plant species have been a part of human culture to improve health [8]. Certainly, animals as therapeutic agents have been contributing significantly to the prevention and treatment of health disorders across the globe [9]. It has been estimated that $8.7 \%$ of the essential chemicals used in protective drugs are animal based [10]. Because of immunological, analgesic, antibacterial, diuretic, anesthetic, and anti-rheumatic properties, insects are essential components of modern

(C) The Author(s). 2018 Open Access This article is distributed under the terms of the Creative Commons Attribution 4.0 International License (http://creativecommons.org/licenses/by/4.0/), which permits unrestricted use, distribution, and 
drugs [11]. Chitosan, derived from exoskeleton of insects, is used as an anticoagulant, to lower cholesterol levels in the blood and to repair tissues [12]. Potential anticancer drugs have been isolated from the wings and legs of Asian sulfur butterflies and Taiwanese stag beetles [13].

Pharmaceutical industries are testing many animal species for drug discovery [14]. The best-known example is of snake venom that inhibits angiotensin-converting enzyme (ACE), responsible for the conversion of angiotensin hormone from an inactive precursor, which causes narrowing the blood vessels and raises blood pressure [15]. Similarly, a number of compounds having a defensive role such as biogenic amines, steroids, alkaloids, and peptides have been reported in the secretions of amphibians [16]. These chemical substances possess diverse pharmacological effects including cardiotoxic, myotoxic, and neurotoxic activities [17].

Wildlife is an important but poorly known source to treat many infectious diseases, particularly the zoonotic disorders [18]. The trade in wildlife for food, medicine, and products and as pets, among other uses, involves hunting and the sale of animals of many species [19-22]. Ethnomedicinal information collected form aboriginal peoples contribute significantly to recognize novel biological resources for commercial utilization, mainly in pharmaceutical industries [23, 24]. In addition, expansion of modern medicines is based on traditional knowledge of indigenous communities. Consequently, documentation of the traditional knowledge of indigenous people is imperative, because in the recent era modern drug development has greatly been affected due to loss of socioeconomic and cultural characteristics of local communities around the globe [4]. Pakistan has a rich diversity of animals including 195 "species of mammals" [25], 668 "species of birds" [26], 195 "species of herptiles" [27], over 1000 "species of marine and fresh water fishes", and 5000 "species of insects" [28]. A number of these species are being utilized in traditional health care. However, ethno-medicinal uses of animal species have rarely been recorded. Furthermore, we imagine that ethnozoological knowledge of local communities residing in settled areas is threatened due to increasing population, urbanization, and industrialization, which should be documented before depletion. Therefore, the current survey aimed to assess and document ethnomedicinal uses of animal species among the local communities of two districts Jhelum and Lahore of the Punjab province, Pakistan.

\section{Methods}

\section{Field sites}

Ethnozoological survey was conducted in 2012 and 2016 in four sub-areas of district Jhelum: Jhelum city, Burha Jungle, Rohtas fort, and Rasool barrage, and four sub-areas of district Lahore: Lahore city, Bara dari, Chung, and head Baloki (Fig. 1).

District Jhelum is located towards North of the river Jhelum and surrounded by district Rawalpindi in the North, Azad Kashmir from the East, Gujrat and Sargodha districts in the South, and district Chakwal from the West $[29,30]$. Total population of the district is 1.223 million, out of which $71 \%$ live in rural areas and the rest of $29 \%$ is urban population [31]. Approximately, $98.5 \%$ of the population is Muslim, while among minorities Christians are in majority with 1\%. Awan, Syed, Kashmiri, Ghakar, Gujjar, Mughal, Jat, and Janjua are the major ethnic groups in this area. Jhelum is a semi-mountainous area, receives $880 \mathrm{~mm}$ mean annual rain fall, and has $23.6{ }^{\circ} \mathrm{C}$ average annual temperature. The inhabitants of Jhelum are agro-pastoralists because of their origin from different parts of Azad and Jammu Kashmir (India). Inhabitants in the rural areas of Jhelum live in mud and brick houses and speak Punjabi and/or Pothohari language. Agriculture, livestock, and mining are the main sources of income. Khewra salt mine in Jhelum is the world's second largest salt mine [30, 32]. District Jhelum is rich in animal diversity, particularly due to the Mangla dam on the Jhelum River. This wetland is an excellent habitat for bird species. Scientists [33] reported 336 species of birds including 153 breeding residents, 115 winter visitors, 15 summer visitors, 39 passage visitors, and 14 occasionally recorded species. The Mangla water reservoir also provides habitat and food for a variety of fish species. The mammalian fauna of the area is mainly of Oriental origin. The main mammalian species belong to Canis, Herpestes, Lepus, Lutra, Manus, Mus, Rattus, Suncus, Sus, Viverricula, and Vulpes genera [34].

Lahore is also called as the heart of Pakistan, because it is the hub for culture in the Punjab region and Pakistan as a whole. District Lahore is located towards the North of the river Ravi and is surrounded by Kasur district in the South, district Sheikhupura in the North West, whereas in the East and North-East it is bordered by Indian Punjab $[29,35]$. According to a recent survey, the total population of the district is 11.33 million. More than $40 \%$ of its inhabitants are below the age of 15 and the same percentage of the population is literate. Almost all inhabitants of this area live in an urban environment. Lahore is the second largest city in Pakistan after Karachi and 32nd largest district in the world. Around 94\% of the population is Muslim comprising Sunni and Shia while $6 \%$ are minorities, i.e., Christians, Hindus, and Sikhs [36]. Majority of the people in the district speak Punjabi, however, in different dialects, which make it a diverse speaking population area. Urdu and English languages are also spoken and understand by a large 


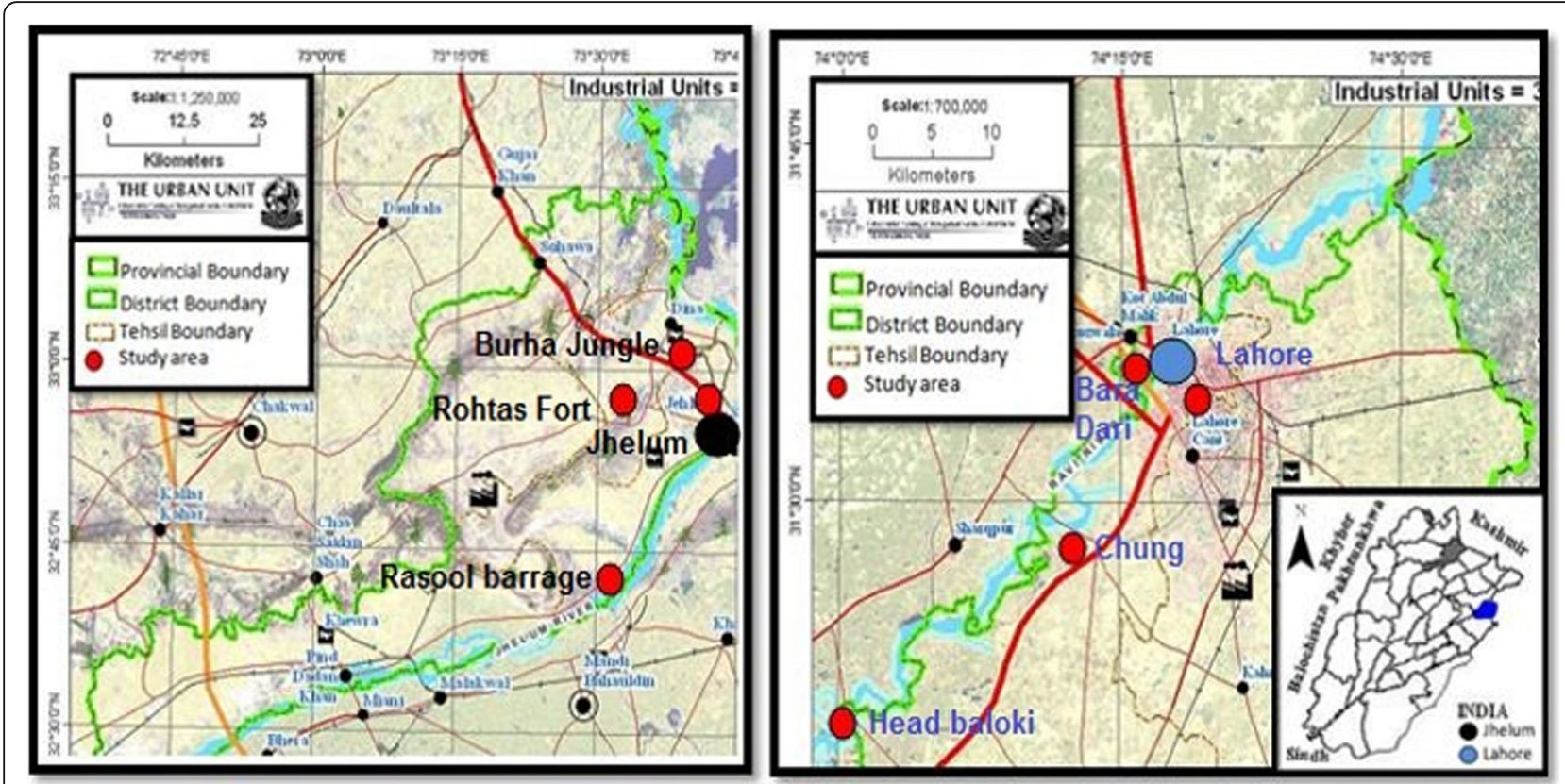

Fig. 1 Map of the study area

number of the population. The average annual rain fall in Lahore district is about $490 \mathrm{~mm}$. The winter in Lahore is cooler than Jhelum with temperature ranging from 1.2 to $15{ }^{\circ} \mathrm{C}$ whereas in summer temperature rises up to $46{ }^{\circ} \mathrm{C}$ $[30,35]$. Nevertheless, Lahore district has greater extension in its urban area. However, still ancient shrines, gardens, cemeteries, traditional buildings, canals, and roads are present, which are the home of many birds, amphibians, and reptiles. In previous records, more than 240 bird species have been documented in Lahore; however, this number is restricted to 85 species now, due to urbanization [37]. Changa Manga forest near Lahore is a wildlife hotspot including wild boar, deer, jackal, nilgai, Asiatic wild cat, and Old World vultures [38]. Increasing population, urbanization, and industrialization depicted great impact on the floral and faunal diversity of Lahore district. Virgin areas of the district supporting natural flora and fauna have been devastated and replaced by buildings, roads, and industries. A greater part of the native flora has been replaced by alien plant species, which is gradually removing the fauna. Such invasion of exotic species poses risk to the biotic uniqueness of the local ecosystems and traditional knowledge of local communities [39]. In a study conducted in Nishtar and Wagah towns of Lahore, about 49 species of birds were reported [40]. In a recent survey, 3 amphibian and 15 reptilian species were reported from Kasur near Lahore [41].

\section{Data collection and analysis}

Before the field survey, prior consent was taken from the Department of Zoology, Women University of Azad
Jammu and Kashmir, Bagh, Pakistan. In addition, we also followed the ethical guidelines of the International Society of Ethnobiology (http://www.ethnobiology.net) during the study. Questionnaires and semi-structured interviews were conducted to document ethnomedicinal uses of animal species. Data were collected from 100 informants in each district including farmers, herdsmen, hunters, teachers, and traditional health practitioners (Table 1). Informants were selected based on their knowledge on medicinal uses of animal species. Mammals, birds, herptiles, and fish species were recognized using field guides "Mammals of Pakistan" [42, 43], "Birds of Pakistan" [44, 45], "Amphibian and Reptiles of Pakistan" [46], and "Freshwater Fishes of Pakistan" [47]. Data on ethnomedicinal uses and cultural values were analyzed using various indices such as frequency of citation (FC), use value (UV), relative importance (RI), fidelity level $(\mathrm{FL})$, similarity index (SI), principal component analysis (PCA), and cluster analysis (CA).

\section{Frequency of citation (FC)}

$\mathrm{FC}$ is the number of informants who reported medicinal uses of each species.

\section{Relative importance (RI)}

The relative importance (RI) of animal species cited by the informants is calculated as follows:

$$
\mathrm{RI}=\mathrm{PP}+\mathrm{AC}
$$

where PP is the number of pharmacological properties (reported specific ailments) attributed to a species 
Table 1 Ethnographic data of local informants

\begin{tabular}{|c|c|c|c|}
\hline Variables & Demographic categories & Jhelum & Lahore \\
\hline \multirow[t]{2}{*}{ Gender } & Male & 100 & 99 \\
\hline & Female & 0 & 1 \\
\hline \multirow[t]{5}{*}{ Experience } & Health practitioners & 19 & 18 \\
\hline & Farmer & 35 & 45 \\
\hline & Teachers & 31 & 15 \\
\hline & Herdsman & 10 & 12 \\
\hline & Hunters & 5 & 9 \\
\hline \multirow[t]{5}{*}{ Age group } & $20-30$ & 5 & 9 \\
\hline & $31-40$ & 27 & 21 \\
\hline & $41-50$ & 36 & 34 \\
\hline & $51-60$ & 26 & 21 \\
\hline & Above 60 & 11 & 15 \\
\hline \multirow[t]{5}{*}{ Education } & Post-graduate & 0 & 1 \\
\hline & Graduate & 12 & 7 \\
\hline & SSC & 20 & 23 \\
\hline & Primary & 34 & 45 \\
\hline & Illiterate & 34 & 24 \\
\hline \multirow[t]{2}{*}{ Residence } & Rural & 77 & 65 \\
\hline & Urban & 23 & 35 \\
\hline \multirow[t]{2}{*}{ Religious background } & Muslim & 98 & 99 \\
\hline & Non-Muslim & 2 & 1 \\
\hline
\end{tabular}

divided by the maximum number of properties attributed to the most resourceful species (species with the highest number of properties). AC is the number of ailment categories treated by a given species divided by the maximum number of ailment categories treated by the most resourceful species. A value of 2 is the highest possible value for relative importance (RI) indicating the most versatile species with the greatest number of medicinal properties [19].

\section{Fidelity level (FL)}

The value of FL highlights the percentage of informants who declare the similar uses of some species [48]. It is calculated by

$$
\mathrm{FL}(\%)=(\mathrm{Np} / N) \times 100
$$

where $\mathrm{Np}$ is the informants' number, calming medicinal use of animal species contrary to a specific disease and $N$ is the total number of informants.

\section{Use value (UV)}

The use value (UV) can be used to prove the relative importance of species. UV of a species is calculated using the equation:

$$
\mathrm{UV}=\sum U / n
$$

where UV is the use value of a species, $n$ is the number of citations per species, and $U$ is the number of informants [49, 50].

Similarity index (SI)

Similarity index (SI) is calculated using the formula:

$$
\mathrm{SI}=M_{\mathrm{s}} / M_{\mathrm{t}}(0 \mathrm{SI} \leq 1)
$$

where $M_{\mathrm{s}}$ is the similar number of medicinal applications in present and previous research records of a species and $M_{\mathrm{t}}$ is the total number of medicinal applications in present research records.

\section{Statistical analysis}

Data on traditional uses of animal species to treat various ailments were statistically analyzed using principal component analysis (PCA) and cluster analysis (CA) methods with the help of statistical software as described earlier [51].

\section{Results and discussion Ethnography}

The data were collected from male Muslims (98\%) and non-Muslims (2\%) in Jhelum, with both genders male (99\%) and female (1\%) with religion as Muslims (99\%) and non-Muslims (1\%) in Lahore. The respondents have different occupations as health practitioners, farmer, teachers, herdsman, and hunters from both districts. They have the education as primary, illiterate, SSC, graduate, and post-graduate. Most of the respondents have age 41-50, while lowest age respondents belong to 20-30-year age in both districts. Most of the respondents belong to almost two thirds from rural and the other from the urban area in both districts Jhelum and Lahore (Table 1).

\section{Ethnomedicinal application of animal species}

The inhabitants of the study area possess significant traditional knowledge and use different animals to treat various health disorders. Out of 57 animal species, 55 were used in Jhelum and 54 in Lahore to treat nervous disorders, paralysis, joint pain, asthma, and fever and to heal wounds and used as aphrodisiacs (Table 2). Nutritional deficiency, lack of a hygienic environment, and social evils may attribute to the high prevalence of these diseases in both study areas. Bufo stomaticus (Indus valley toad), Heteropneustes fossilis (scorpion cat-fish), Lissemys punctate andersoni (Indian flap-shelled turtle), and Oligochaeta spp. (earthworms) were the commonly utilized species in Lahore. Conversely, the inhabitants of Jhelum use Hoplobatrachus tigerinus, (Indian bullfrog), 


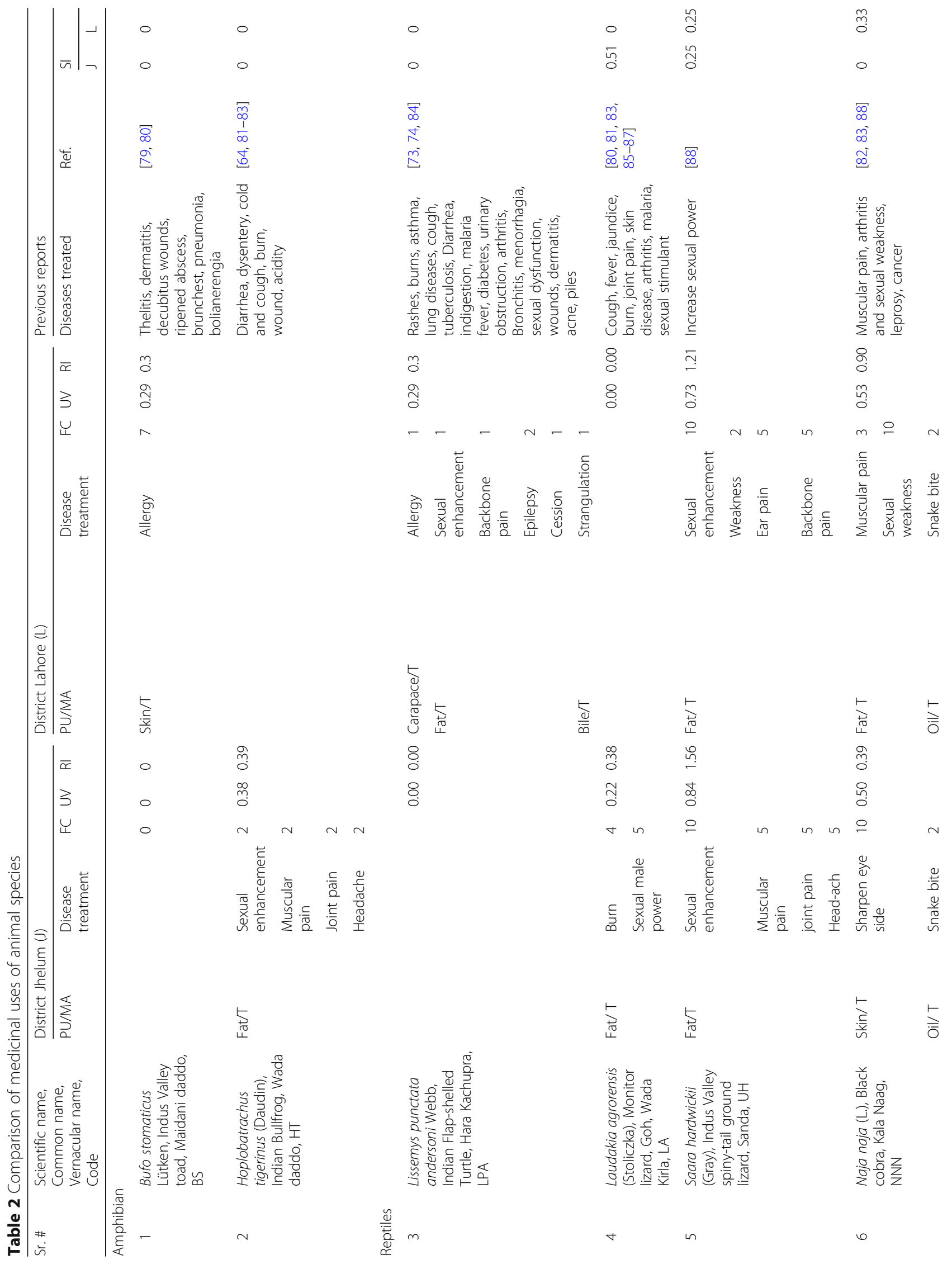




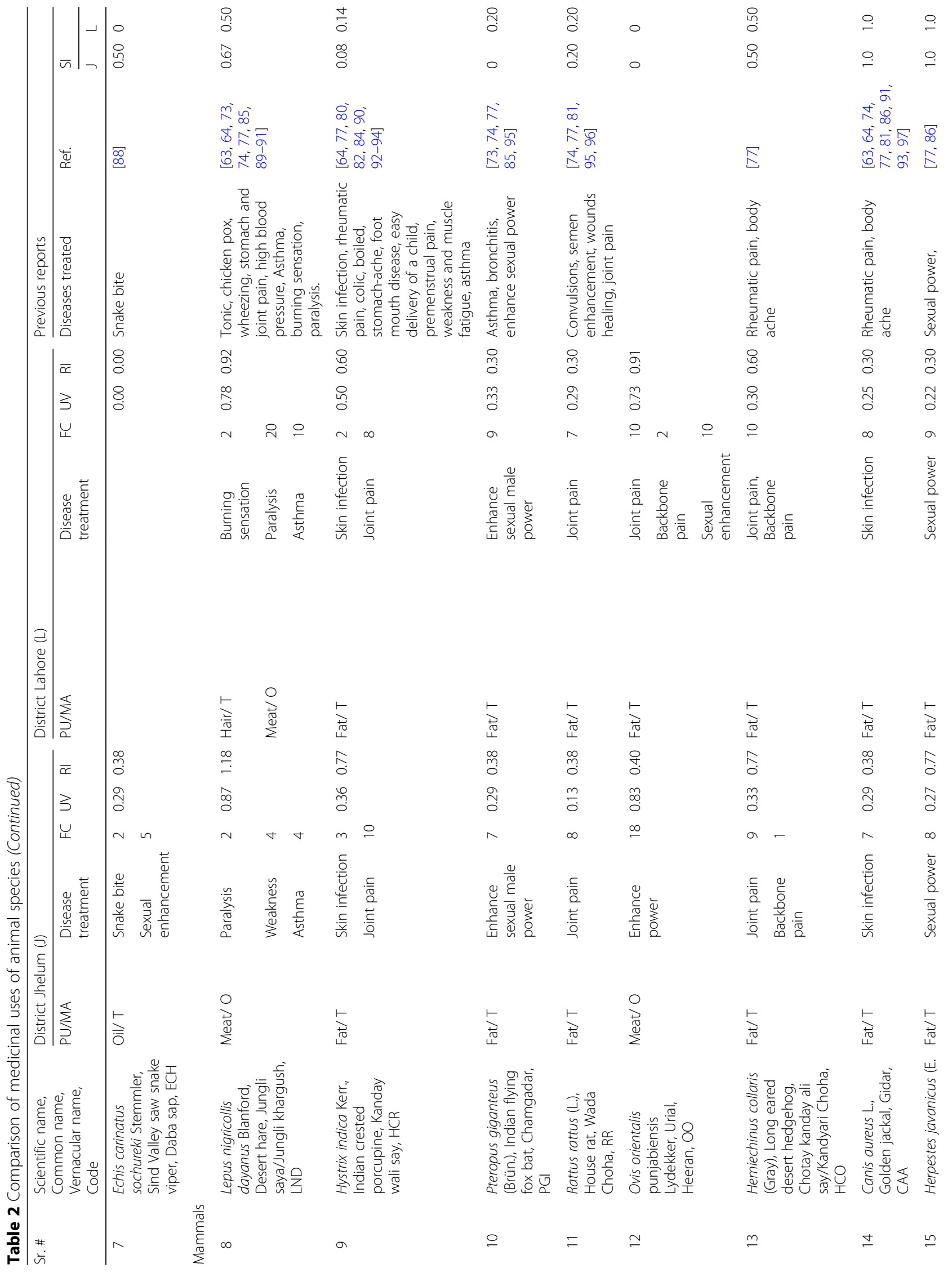


Altaf et al. Journal of Ethnobiology and Ethnomedicine (2018) 14:55

Page 7 of 25

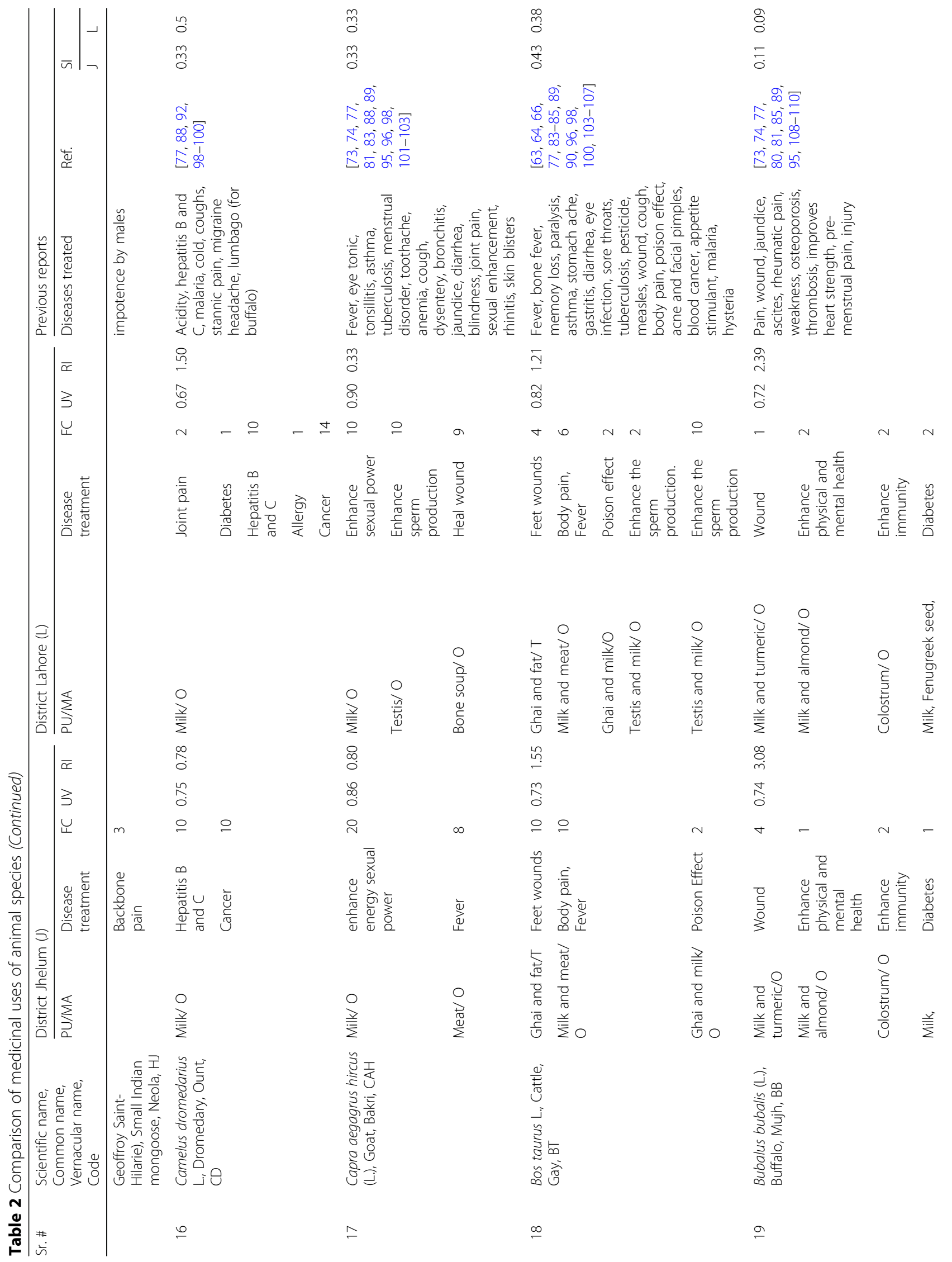




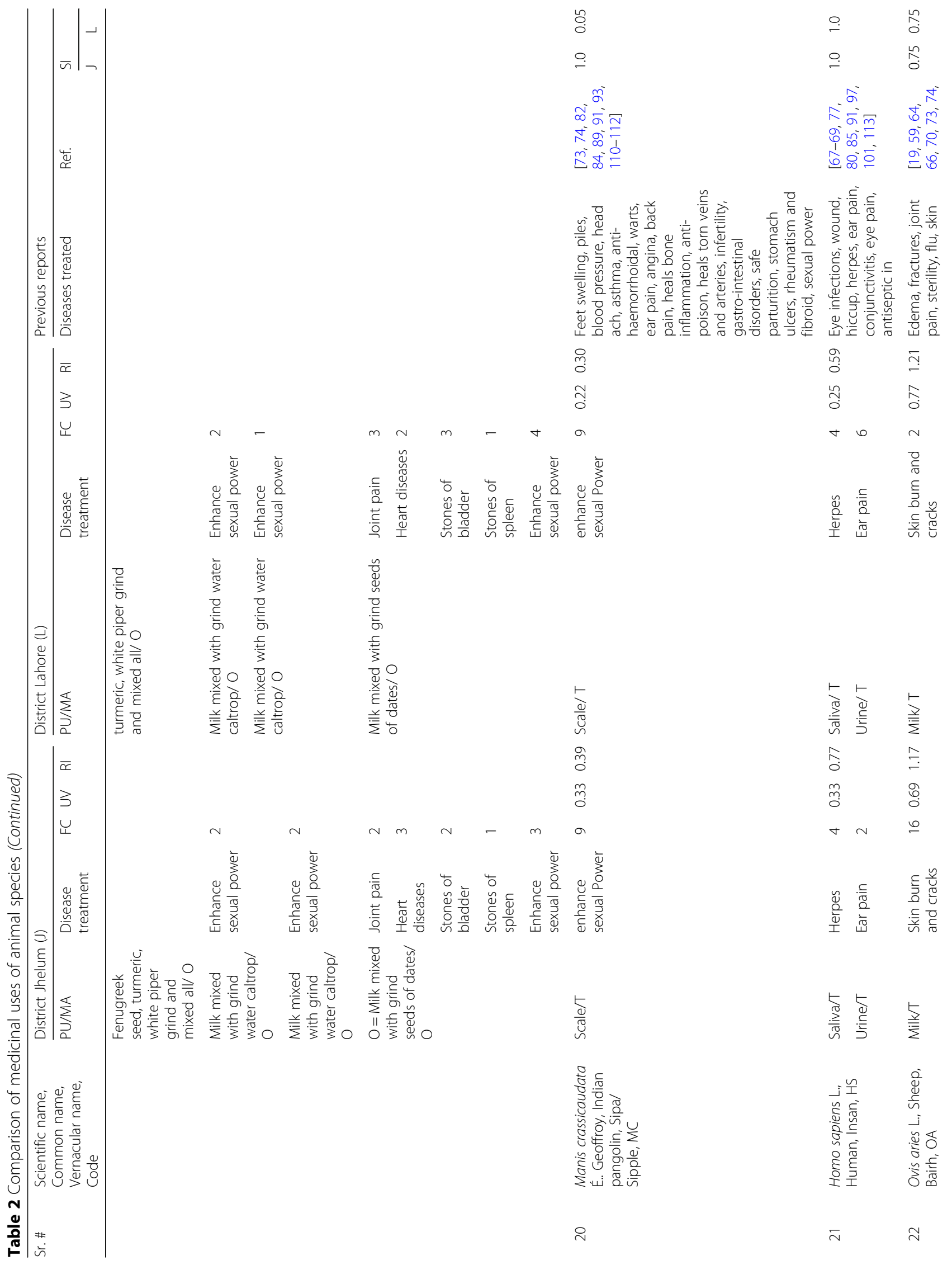




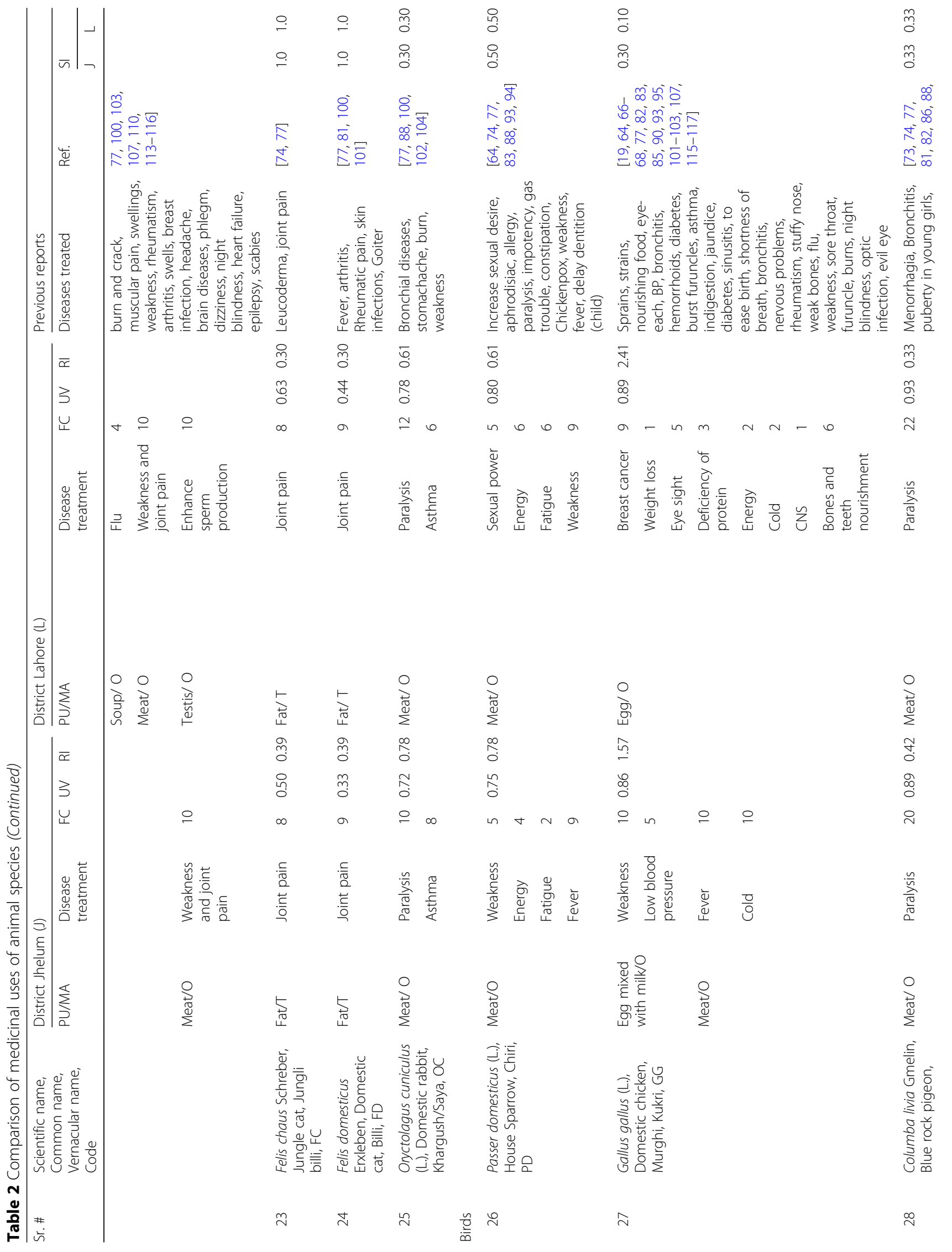




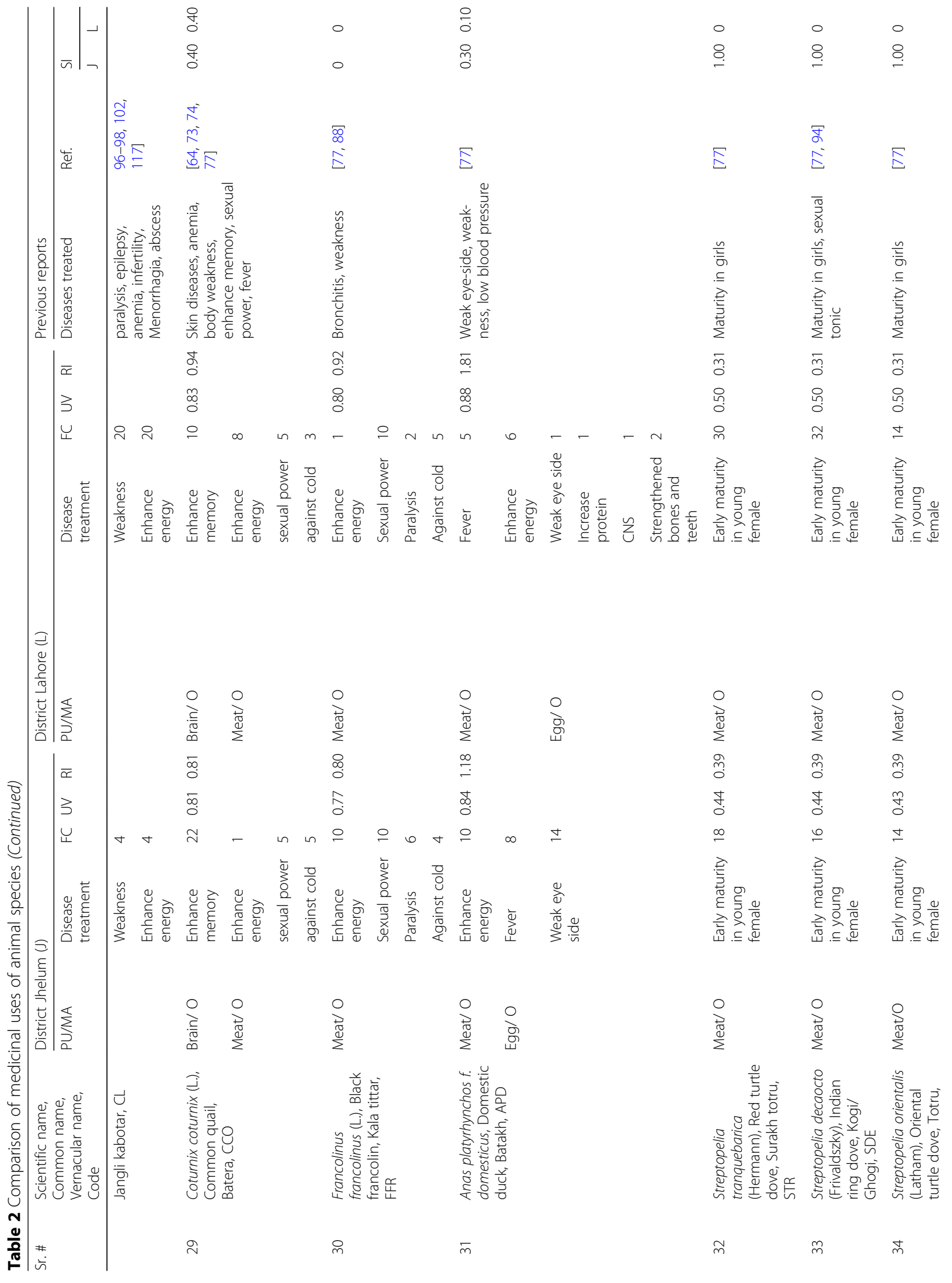




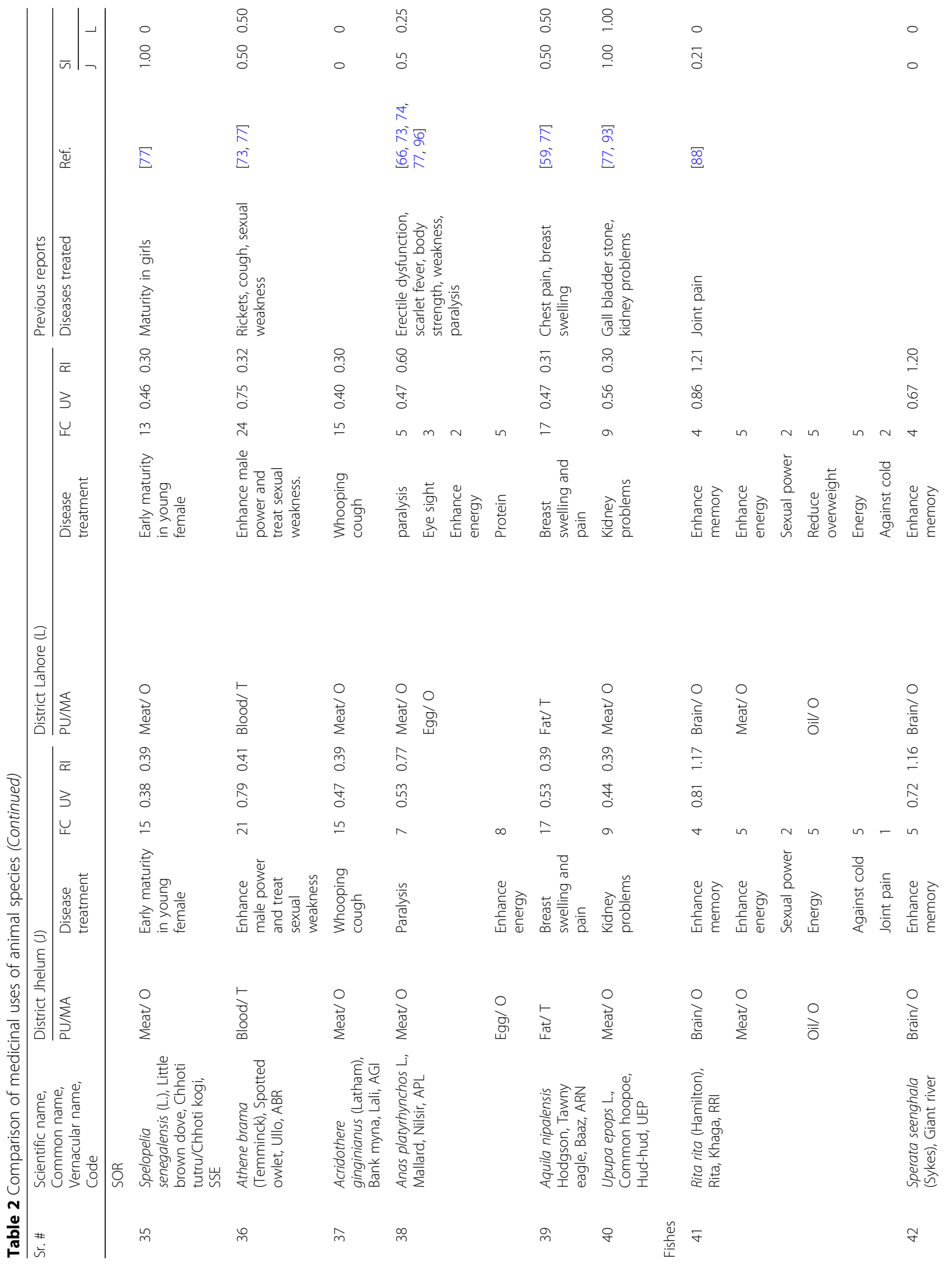




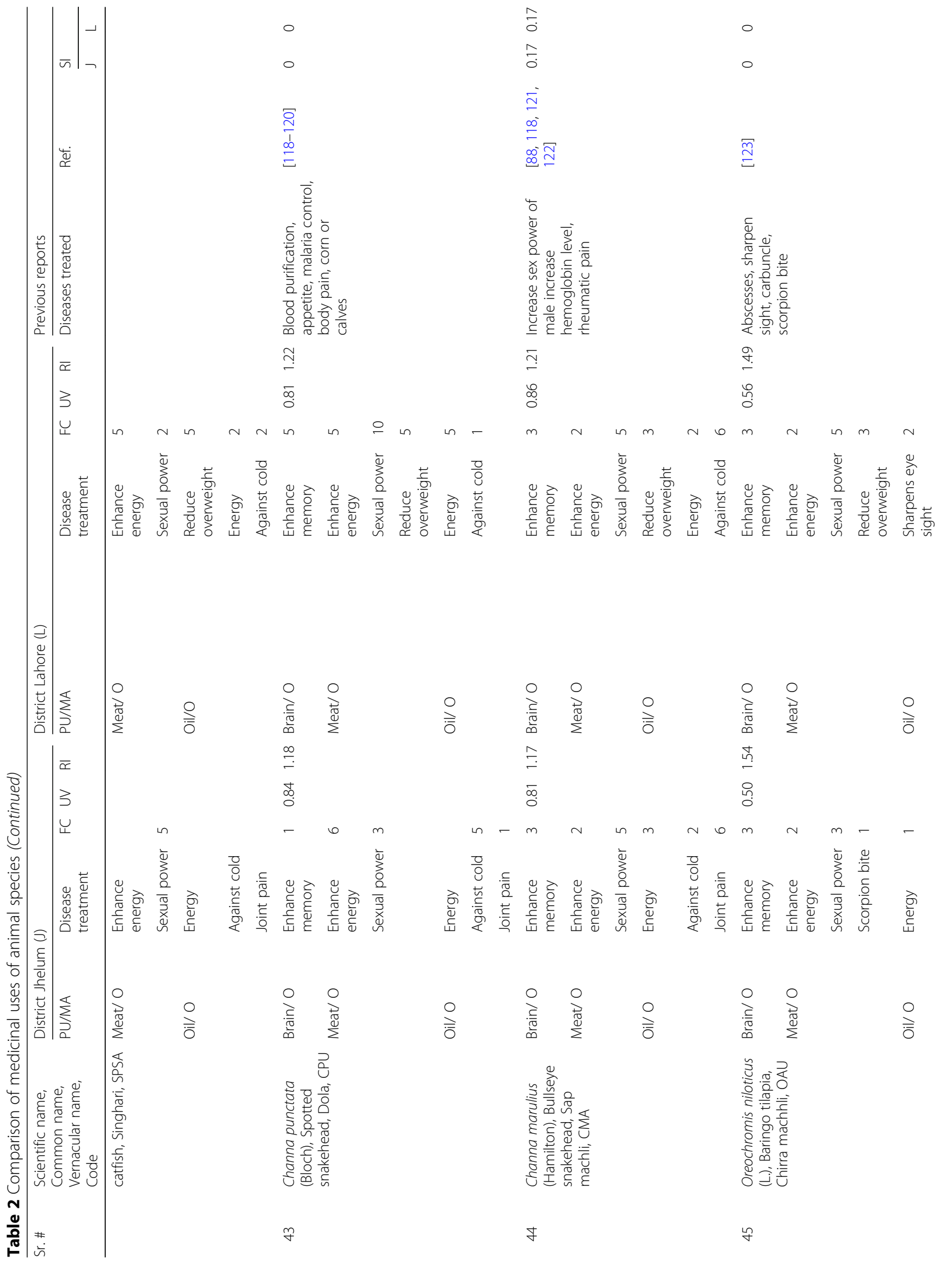




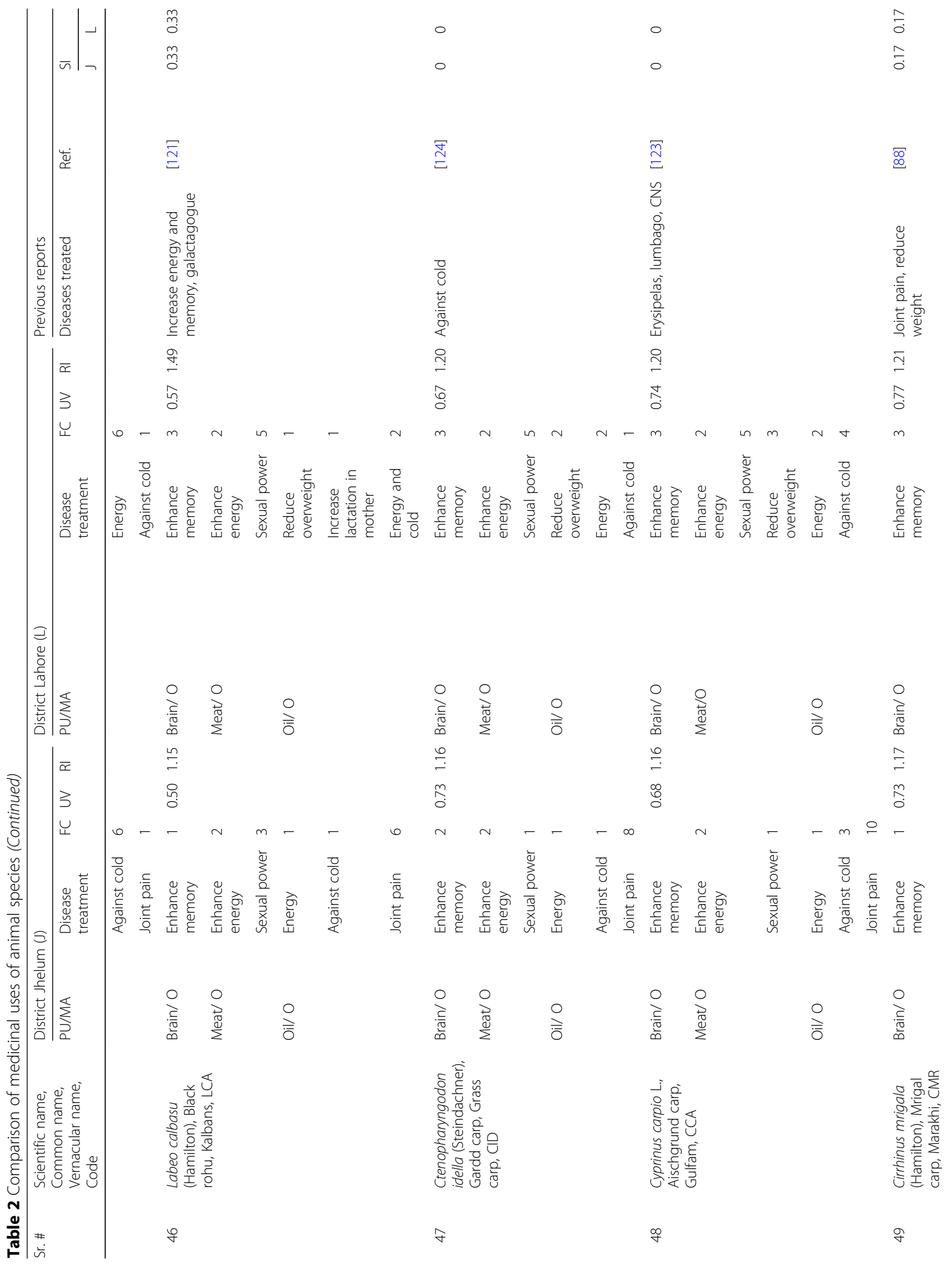




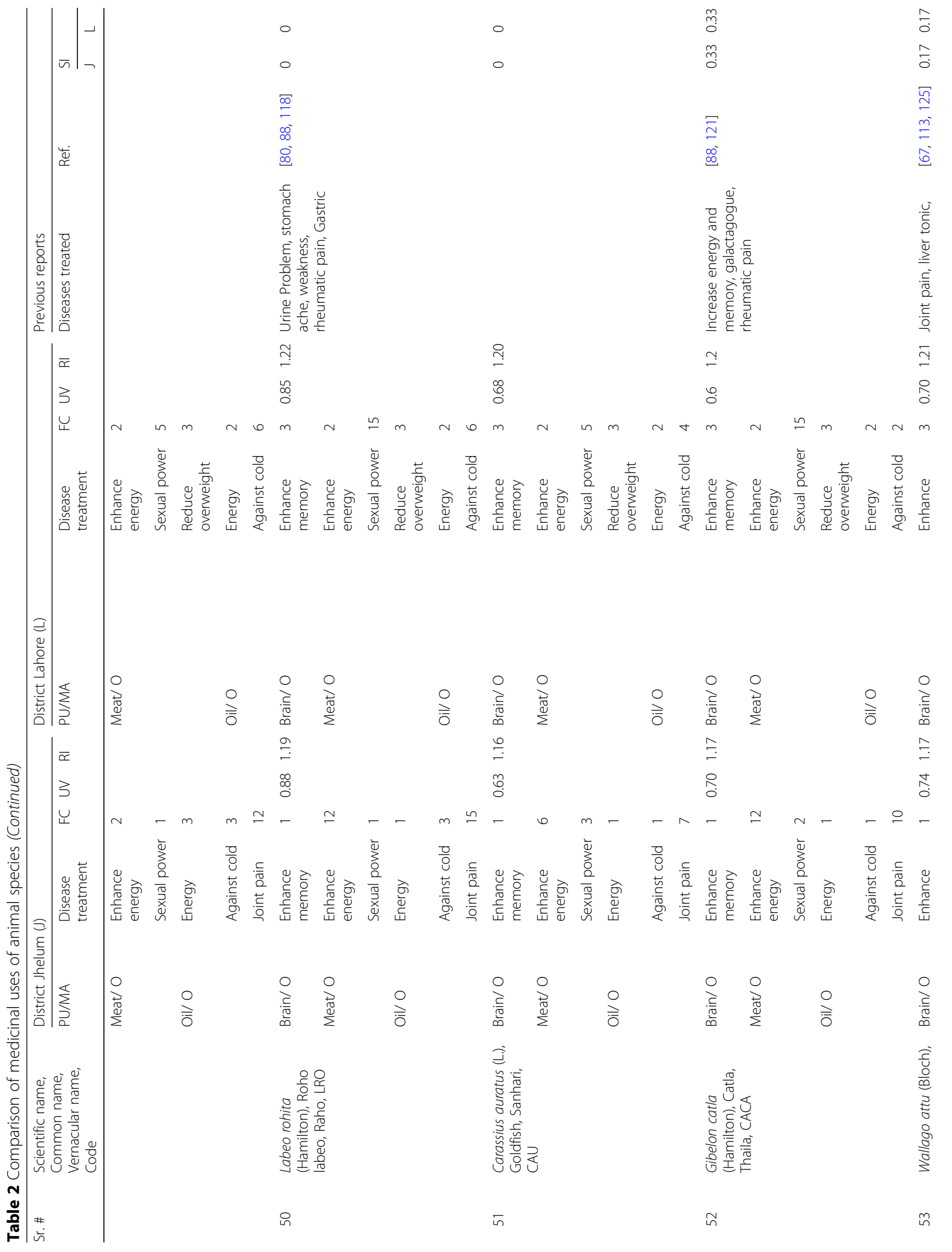




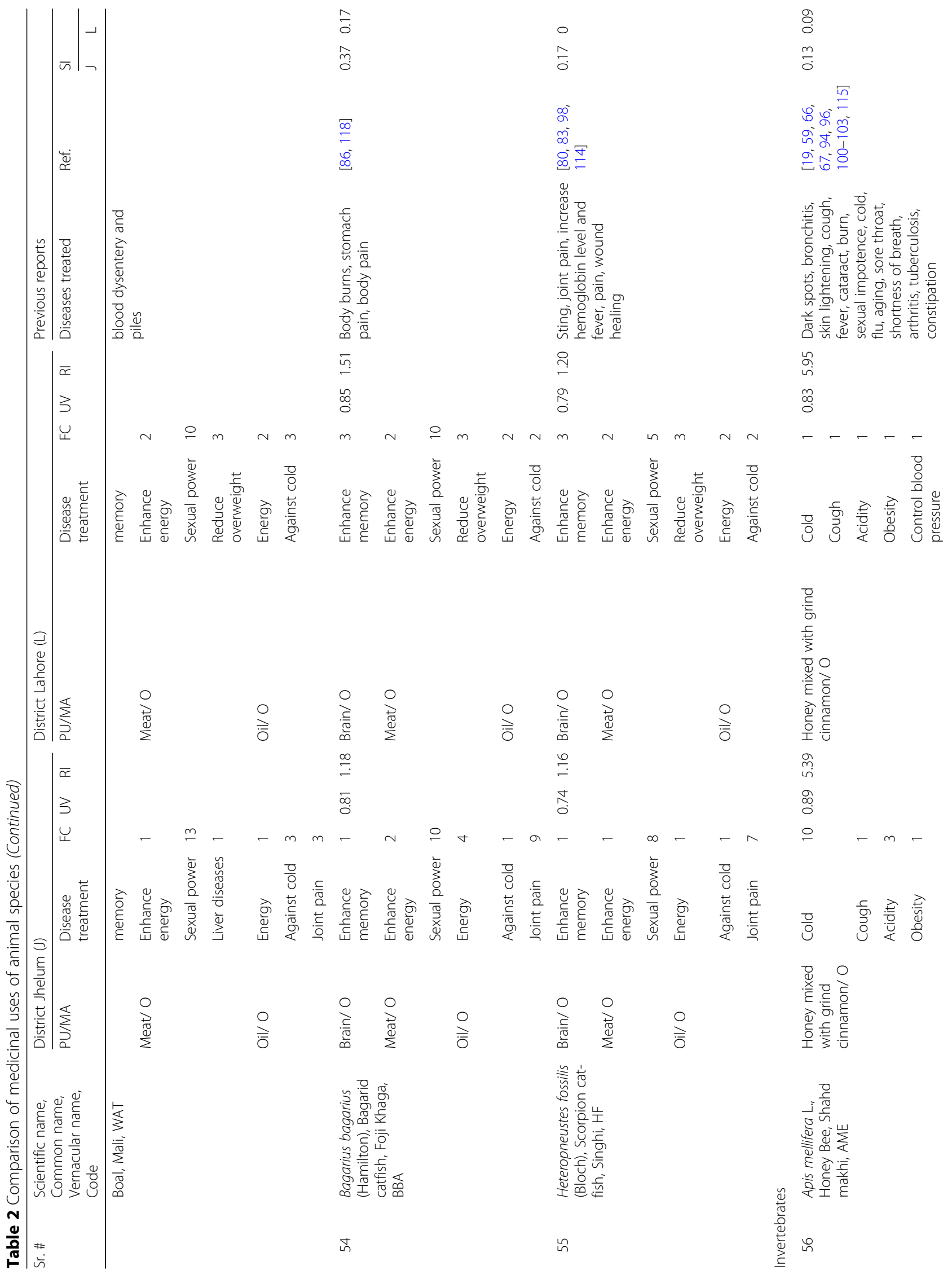




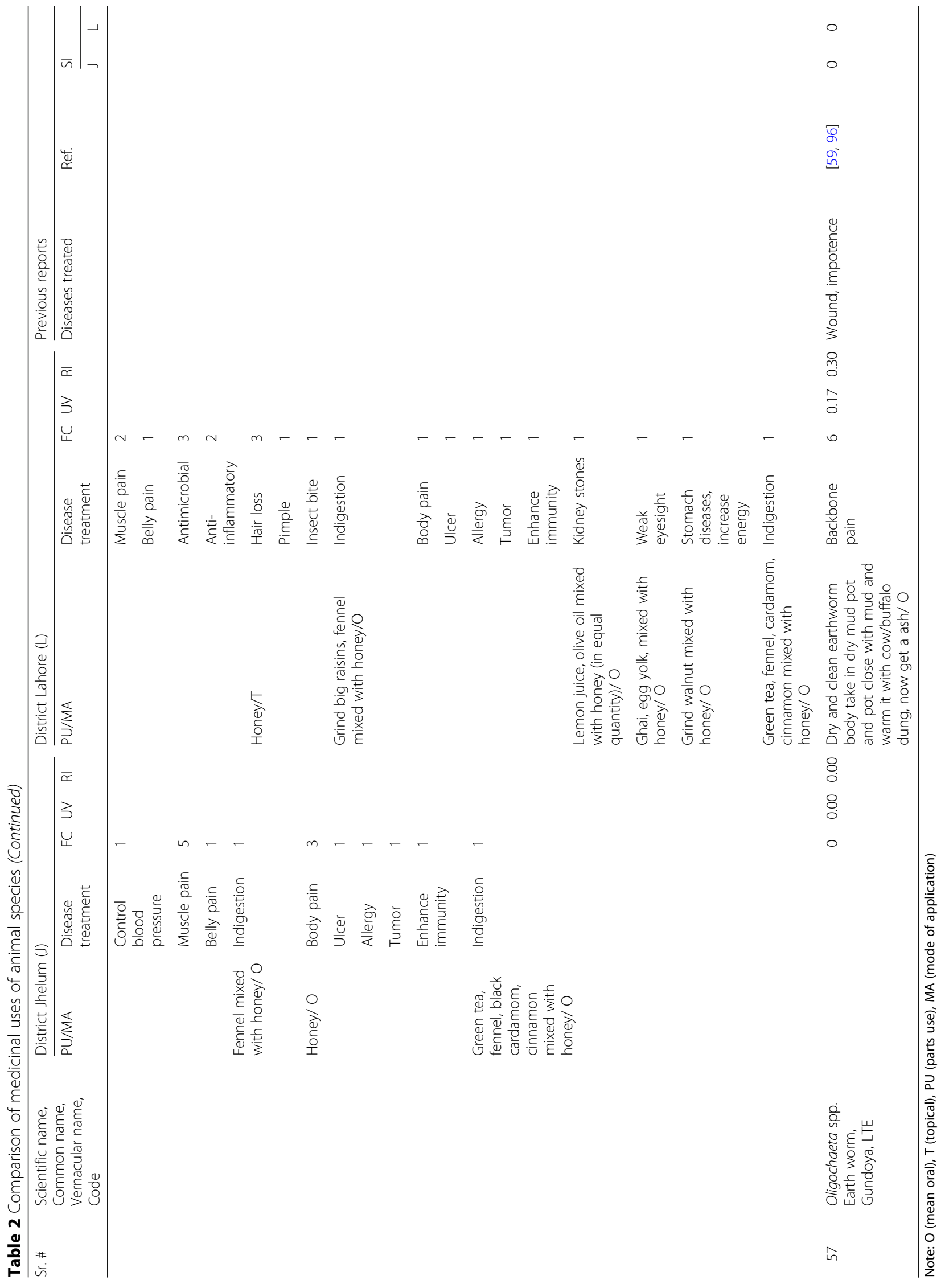


Naja naja naja, (black cobra), Pteropus giganteus (Indian flying fox bat), and Bagarius bagarius (bag arid catfish) to treat various diseases.

The medicinal uses of Ovis orientalis punjabiensis (urial), Francolinus francolinus (black francolin), Sperata sarwari (giant river catfish), Channa punctate (snake head), Oreochromis niloticus (baringo tilapia), Ctenopharyngodon idella (gradd carp), Cyprinus carpio (aischgrund carp), Labeo rohita (roho labeo), and Carassius auratus (goldfish) were reported for the first time from the study areas. These species are used to treat allergy, epilepsy, fever, joint pain, and backache and to enhance memory and as aphrodisiac. Additionally, they have a zero similarity index with previous reports. However, some species such as Canis aureus (golden jackal), Herpestes javanicus (small Indian mongoose), Homo sapiens, (human), Felis chaus (jungle cat), Felis domesticus (domestic cat), Upupa epops (common hoopoe), Manis crassicaudata (Indian pangolin), Streptopelia tranquebarica (red turtle dove), Streptopelia decaocto (Indian ring dove), Streptopelia orientalis (oriental turtle dove), and Spelopelia senegalensis (little brown dove) exhibited the highest similarity index $(\mathrm{SI}=1)$ with previous studies.

\section{Body part(s)}

Meat was the most utilized body part and used in 36 recipes in Jhelum and 34 recipes in Lahore (Fig. 2), followed by oil and brain used in 20 and 16 recipes, respectively, in both districts, and fat used in 15 and 16 recipes in Jhelum and Lahore respectively. Milk, skin, bones, eggs, scale, saliva, blood, urine, testis, and carapace were used in less than five recipes. Local inhabitants of Lahore and Jhelum use chopped brains of different species such as common quail, rita, giant river catfish, spotted snakehead, bulls eye snakehead, baringo tilapia, black rohu, gradd carp, aischgrund carp, mrigal carp, Roho labeo, goldfish, catla, boal, bagarid catfish, and scorpion cat-fish to enhance the efficiency of the brain and nervous system. Likewise, testis of Capra aegagrus hircus (goat), Bos taurus (cattle), and Ovis aries, (sheep) are used to enhance the sperm production. However, these uses were more common in Lahore compared to Jhelum. Eggs of Gallus gallus (domestic chicken), Anas platyrhynchos domesticus (domestic duck), and Anas platyrhynchos (mallard) are used to treat fever, cold, weakness, low blood pressure, and weak eye side in Jhelum, while in Lahore they are used to treat breast cancer, weight loss, and cold and to enhance the performance of the CNS and strength of bones and teeth.

It has been reported that omega-3 fatty acid in animal fat ore oil reduces inflammation [52]. The present study revealed that inhabitants of the study areas use fat and oil to treat backache, breast swelling, cold, headache, burn, rheumatic pains, snake bite, and skin infections and as a sex stimulant (Figs. 2, 3 and 4). These uses are comparable to previous reports that animal fats or oil are useful in atherosclerosis, neurological disorder, and thrombotic and aging effects $[53,54]$.

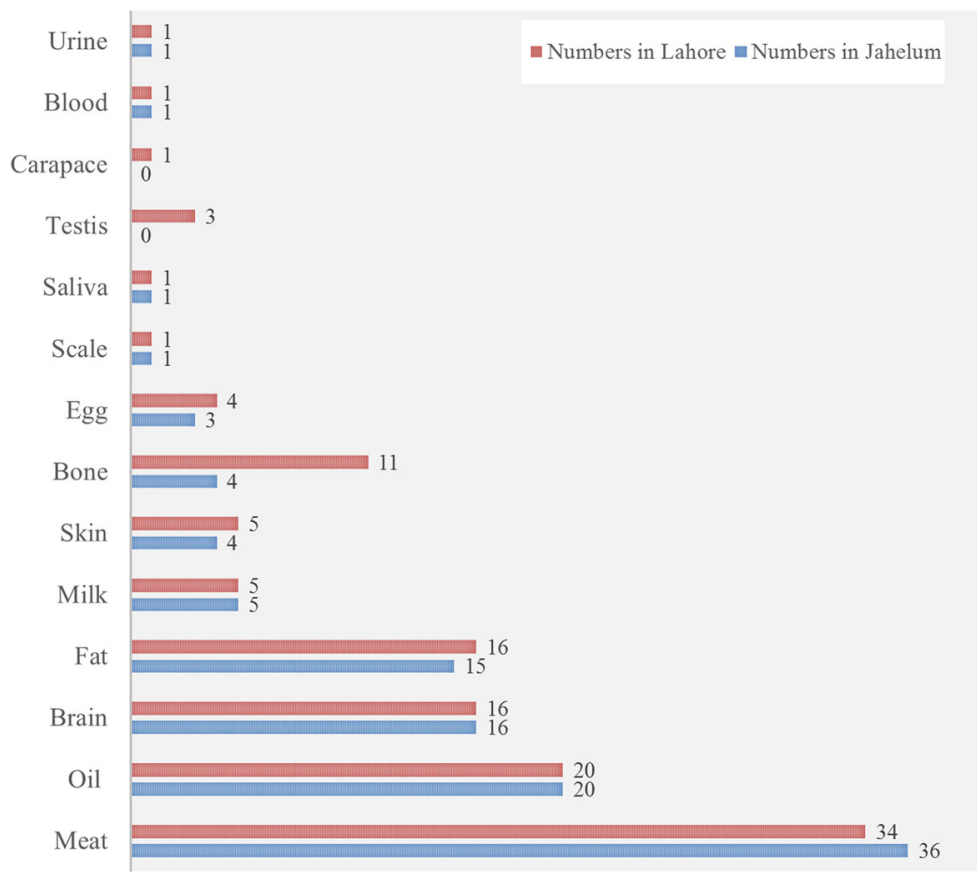

Fig. 2 Body parts of animal species used in different recipes 


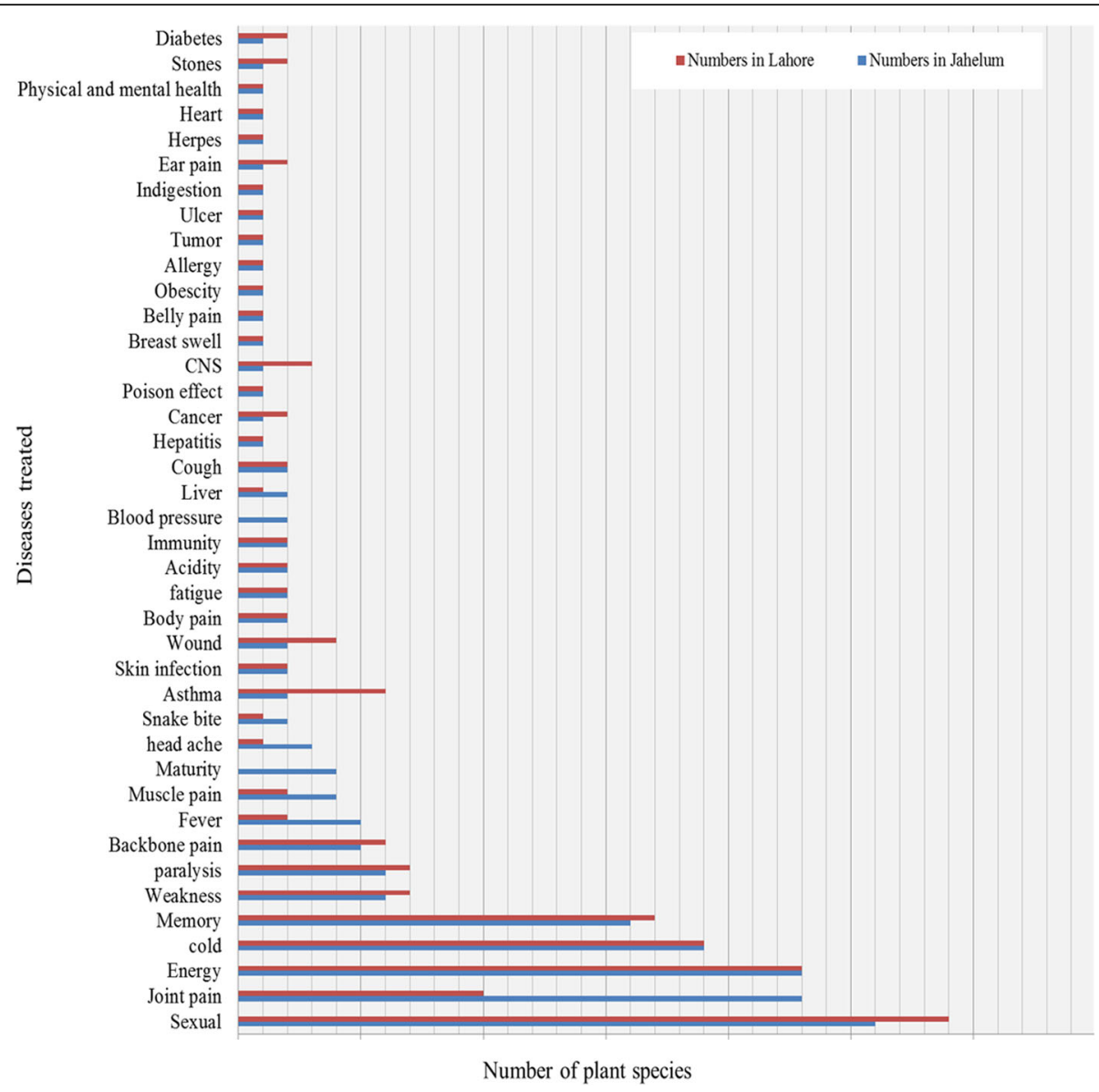

Fig. 3 Number of animal species used to treat various diseases in Jhelum and Lahore

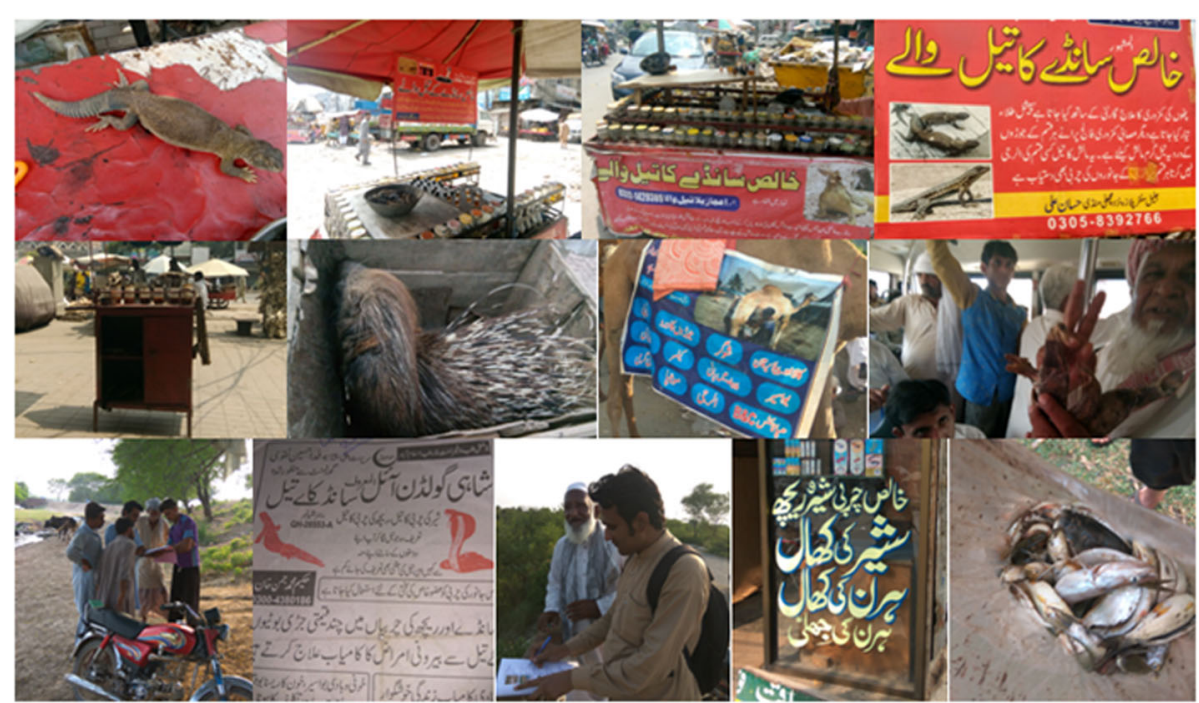

Fig. 4 Pictorial views of traditional uses of animal species in the study areas 
Milk of Bubalus bubalis (buffalo), Bos taurus (cattle), Capra aegagrus hircus (goat), Camelus dromedarius (dromedary), Equus africanus asinus (donkey), and Ovis aries (sheep) is used as a sexual stimulant and antidote; to treat fever, diabetes, blood pressure, backache, and joint pain; for fertility; and to expel kidney stones. It is well known that milk contains high levels of proteins, vitamins, lipids, and minerals, which reduce joint pain, strengthen the body, and increase sexual potency [55-59].

The inhabitant of Lahore use bone soup of Capra aegagrus hircus (goat) to heal internal wounds and fractures (Figs. 4 and 5). This confirms that matrix contains up to 95\% collagen fibers, elastic protein, and inorganic minerals like calcium phosphate, which improves fracture resistance [60]. Local communities use scales of Indian pangolin (Manis crassicaudata) as a sexual stimulant (in both districts) and to remove hook worms (in Lahore only). The health benefits of Pangolin scales might be due to the presence of different chemical constituents such as cholesterol, stearic acid, volatile oil, minerals, proteins, glycine, isoleucine, leucine, lysine, proline, serine, tyrosine, and valine amino acids among several others [61]. However, due to illegal hunting and extensive use in traditional medicines, Indian pangolin is at the verge of extinction and has been included in "Red Listed" species by the International Union for Conservation of Nature (IUCN) [62].

Human's urine is used against herpes and to treat ear pain in both districts. It has been known that the urine of cattle, dromedary, sheep, goat, hyrax, rhinoceros, and ass is also useful in the treatment of acne, asthma, anemia, antifungal, burn, back pain, chronic ailment, disinfection, foot diseases, fever, skin infections, TB, mouth infection, syphilis, rashes, CNS, memory loss, throat, and ear and eye infection [20,63-74]. In addition, urine of dromedary inhibits enhancement of apoptosis, cell
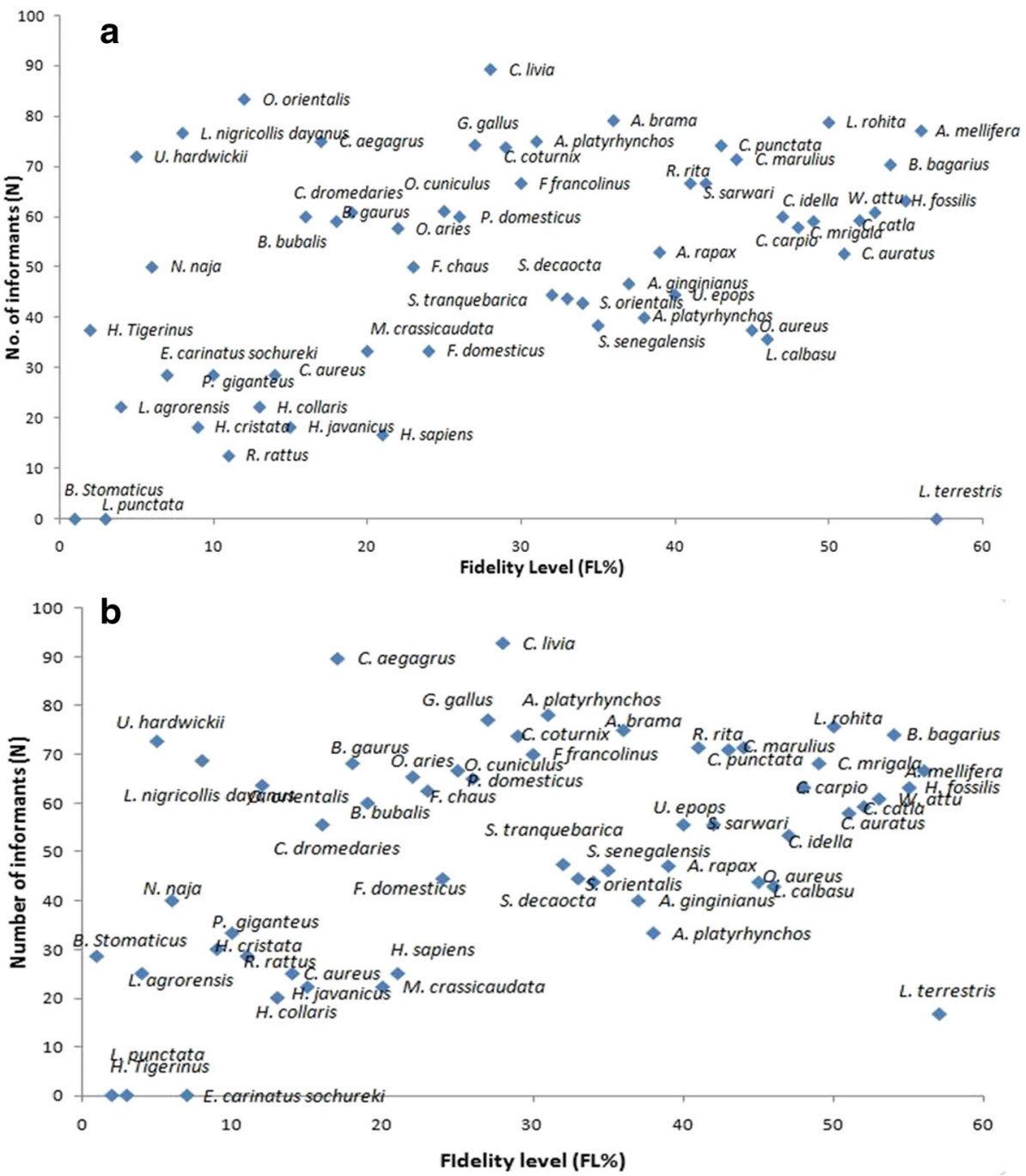

Fig. 5 Relationship between informant numbers and the number of application in study sites. (a) for Jehlum and (b) for Lahore 
Table 3 Comparison of fidelity level in the both study areas

\begin{tabular}{|c|c|c|c|}
\hline S\# & Scientific name & Jhelum (FL) & Lahore (FL) \\
\hline 1 & Bufo Stomaticus & 0.000 & 28.57 \\
\hline 2 & Hoplobatrachus Tigerinus & 37.50 & 0.000 \\
\hline 3 & Lissemys punctata andersoni & 0.00 & 25.00 \\
\hline 4 & Laudakia agrorensis & 22.22 & 0.000 \\
\hline 5 & Uromastyx hardwickii & 72.00 & 72.73 \\
\hline 6 & Naja naja naja & 50.00 & 40.00 \\
\hline 7 & Echis carinatus sochureki & 28.57 & 0.000 \\
\hline 8 & Lepus nigricollis dayanus & 76.67 & 68.75 \\
\hline 9 & Hystrix indica & 18.18 & 30.00 \\
\hline 10 & Pteropus giganteus & 28.57 & 33.33 \\
\hline 11 & Rattus rattus & 12.50 & 28.57 \\
\hline 12 & Ovis orientalis punjabiensis & 83.33 & 63.64 \\
\hline 13 & Hemiechinus collaris & 22.22 & 20.00 \\
\hline 14 & Canis aureus & 28.57 & 25.00 \\
\hline 15 & Herpestes javanicus & 18.18 & 22.22 \\
\hline 16 & Camelus dromedarius & 60.00 & 55.56 \\
\hline 17 & Capra aegagrus hircus & 75.00 & 89.66 \\
\hline 18 & Bos taurus & 59.09 & 68.18 \\
\hline 19 & Bubalus bubalis & 60.87 & 60.00 \\
\hline 20 & Manis crassicaudata & 33.33 & 22.22 \\
\hline 21 & Homo sapiens & 16.67 & 25.00 \\
\hline 22 & Ovis aries & 57.69 & 65.38 \\
\hline 23 & Felis chaus & 50.00 & 62.50 \\
\hline 24 & Felis domesticus & 33.33 & 44.44 \\
\hline 25 & Oryctolagus cuniculus & 61.11 & 66.67 \\
\hline 26 & Passer domesticus & 60.00 & 65.00 \\
\hline 27 & Gallus gallus & 74.29 & 77.14 \\
\hline 28 & Columba livia & 89.29 & 92.86 \\
\hline 29 & Coturnix coturnix & 73.81 & 73.81 \\
\hline 30 & Francolinus francolinus & 66.67 & 70.00 \\
\hline 31 & Anas platyrhynchos f. domesticus & 75.00 & 78.13 \\
\hline 32 & Streptopelia tranquebarica & 44.44 & 47.37 \\
\hline 33 & Streptopelia decaocto & 43.75 & 44.44 \\
\hline 34 & Streptopelia orientalis & 42.86 & 43.75 \\
\hline 35 & Spelopeliasenegalensis & 38.46 & 46.15 \\
\hline 36 & Athene brama & 79.17 & 75.00 \\
\hline 37 & Acridothere ginginianus & 46.67 & 40.00 \\
\hline 38 & Anas platyrhynchos & 40.00 & 33.33 \\
\hline 39 & Aquila nipalensis & 52.94 & 47.06 \\
\hline 40 & Upupa epops & 44.44 & 55.56 \\
\hline 41 & Rita rita & 66.67 & 71.43 \\
\hline 42 & Sperata seenghala & 66.67 & 55.56 \\
\hline 43 & Channa punctata & 74.19 & 70.97 \\
\hline 44 & Channa marulius & 71.43 & 71.43 \\
\hline
\end{tabular}

Table 3 Comparison of fidelity level in the both study areas (Continued)

\begin{tabular}{llll}
\hline S\# & Scientific name & Jhelum (FL) & Lahore (FL) \\
\hline 45 & Oreochromis niloticus & 37.50 & 43.75 \\
46 & Labeo calbasu & 35.71 & 42.86 \\
47 & Ctenopharyngodon idella & 60.00 & 53.33 \\
48 & Cyprinus carpio & 57.89 & 63.16 \\
49 & Cirrhinus mrigala & 59.09 & 68.18 \\
50 & Labeo rohita & 78.79 & 75.76 \\
51 & Carassius auratus & 52.63 & 57.89 \\
52 & Gibelon catla & 59.26 & 59.26 \\
53 & Wallago attu & 60.87 & 60.87 \\
54 & Bagarius bagarius & 70.37 & 74.07 \\
55 & Heteropneustes fossilis & 63.16 & 63.16 \\
56 & Apis mellifera & 77.14 & 66.67 \\
57 & Oligochaeta spp. & 0.000 & 16.67 \\
\hline
\end{tabular}

proliferation, and control of cyclin-dependent kinase inhibitor p21 [65] and has high resistance against heat and fungal diseases [72].

\section{Frequency of citation (FC)}

Animal species, reported by the maximum number of informants as frequently used to treat various diseases, have high frequency of citation (FC) which ranged from 1 to 32 (Table 2). In different areas of district Lahore, Streptopelia decaocto (Indian ring dove) and S. tranquebarica (red turtle dove) were reported as the most frequently utilized species for maturity in young girls with $\mathrm{FC}=32$ each. Athene brama (spotted owlet) and Columba livia (blue rock pigeon) were also among the commonly used species with FC value of 24 and 22, respectively. In different localities of Jhelum district, Coturnix coturnix (common quail) with $\mathrm{FC}=22$ was the most commonly used species for the enhancement of memory followed Athene brama (spotted owlet), Columba livia (blue rock pigeon), and Capra aegagrus (goat) which have FC values of 21,20 , and 20, respectively, whereas the lowest $\mathrm{FC}=1$ was calculated for Homo sapiens (human) from Jhelum and earthworms from Lahore.

\section{Fidelity level (FL)}

Fidelity level (FL) is used to identify species that are most preferred by the inhabitants to treatment of certain ailments. Animal species with topmost medicinal uses in a particular area have maximum fidelity level $[75,76]$. The fidelity levels of animal species used by the inhabitants of Lahore and Jhelum districts are given in Table 3. Among the species reported from Lahore: Columba livia (blue rock pigeon) depicted highest FL (92.86\%), followed by Capra aegagrus (goat) and Anas platyrhynchos domesticus 

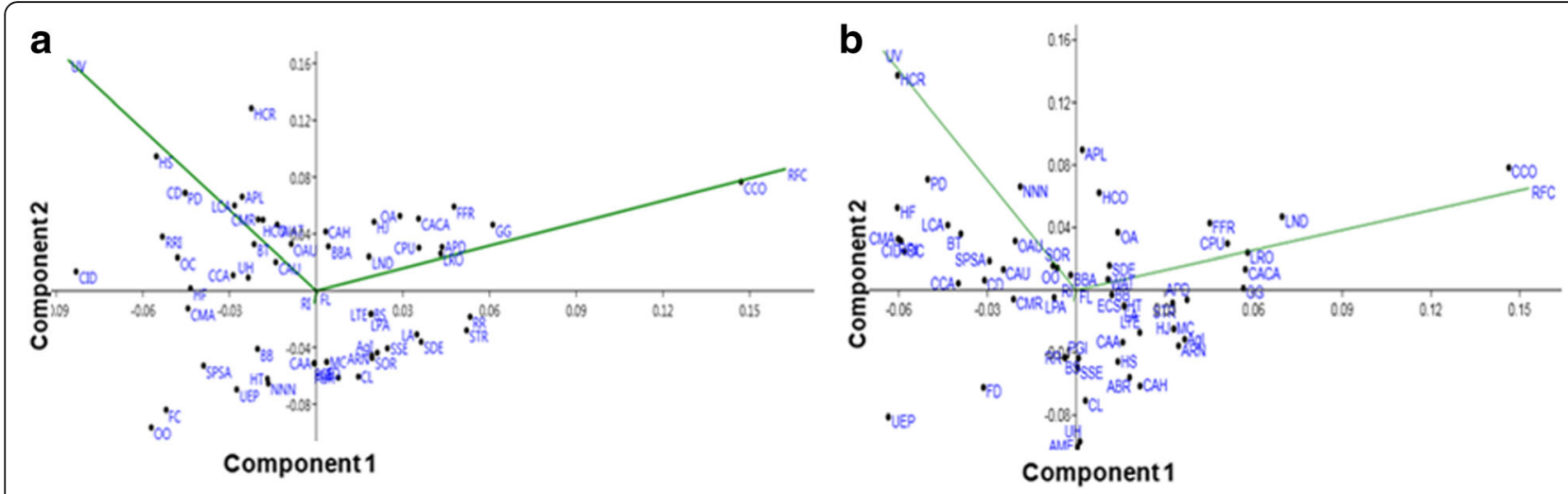

Fig. 6 Principal components analysis (PCA) (code are present in Table 2). The positions of the arrows relative to components 1 and 2 show how strongly independent variables (UV, RFC, FL and RI) are correlated with each other from both districts Jhelum (a) and Lahore (b)

(domestic duck) with percentage $\mathrm{FL}=89.66$ and 78.13, respectively, whereas earthworm had the lowest FL 16.67\%. Among the animal species reported from different parts of Jhelum, Columba livia (blue rock pigeon), Ovis orientalis punjabiensis (urial), and Athene brama (spotted owlet) were dominant with maximum percentage fidelity levels of 89.29, 83.33, and 79.71, respectively. However, Hystrix indica (Indian crested porcupine) had the lowest FL of $18.18 \%$ in Jhelum. The animal species with the highest FL could be used for in-depth chemical profiling and pharmaceutical properties. This will authenticate not only the medicinal worth of these species but could also be useful for novel animal-based drug discovery. Altaf et al. [77] document that the species B. taurus, Oryctolagus cuniculus, Ovis aries, A. platyrhynchos domesticus, G. gallus, and P. domesticus show 100\% FL.

\section{Relative importance (RI)}

The relative importance of animal species used by the inhabitant of Lahore and Jhelum districts is mentioned in Table 2. Most of the animal species were found to be highly versatile in their uses such as Apis mellifera (honey bee) with RI of 5.95 and 5.39 in Lahore and Jhelum, respectively, followed by Columba livia (blue rock pigeon) having RI of 2.4 (Lahore) and 1.6 (Jhelum) and Uromastyx hardwickii (spiny-tail ground lizard) and Heteropneustes fossilis (singhi) with RI of 1.56 (Jhelum) and 1.5 (Lahore). The maximum RI values might be a sign of high affordability and accessibility of these species in the study areas.

\section{Use value (UV)}

Results of use value (UV) authenticate the relative importance of species or family for a population. This index was anticipated to craft a connotation between each species and the uses allocated to it by analyzing the index in relation to the use groups. Comparative assessment of UV of different animal species among the local communities residing in different parts of Lahore and Jhelum is given in Table 2. Among the reported animal species, the highest UVs of 0.89 and 0.88 were calculated for Columba livia (blue rock pigeon) from Jhelum and Gallus gallus (domestic chicken) from Lahore, whereas the lowest UVs of 1.6 and 0.12 were attained by

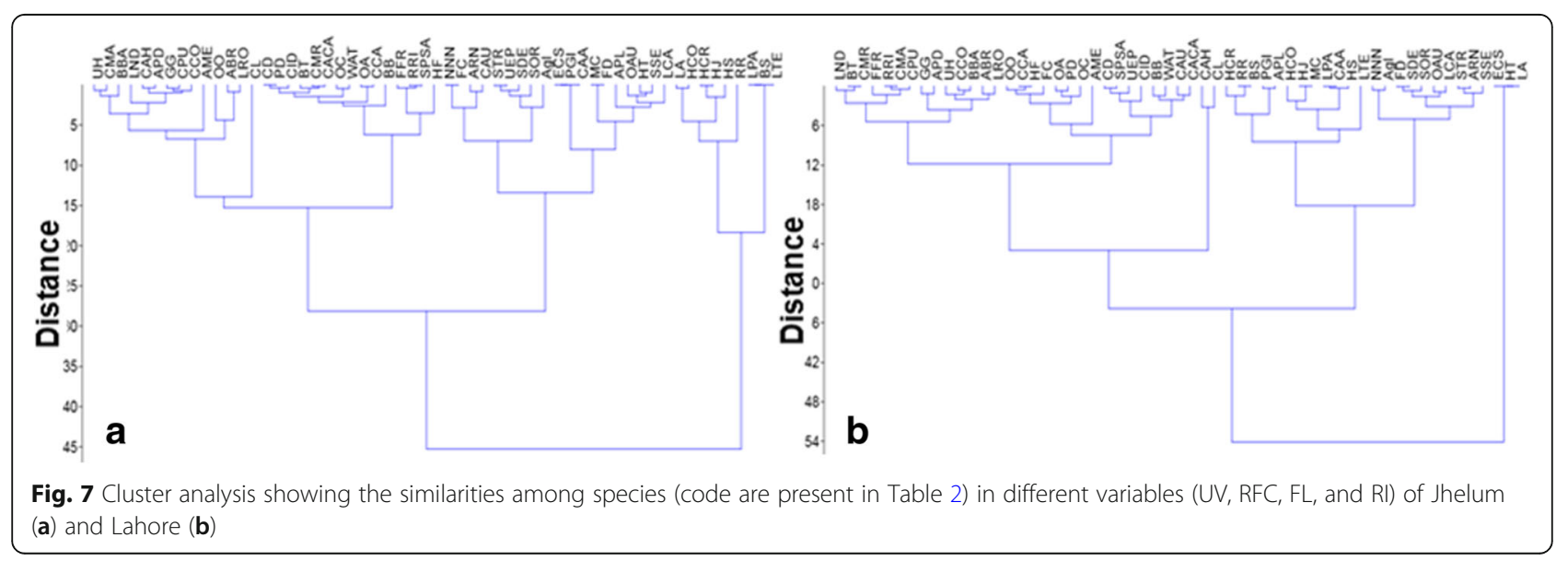


earthworm and Rattus rattus (house rat) in Lahore and Jhelum in respective order. The high UVs of these species certified their consistent use in the treatment of different diseases. In addition, citation by the maximum number of informants and use reports viewing that these species are well known and commonly utilized for medicinal purpose in the study areas.

\section{Principal component analysis (PCA) and cluster analysis (CA)}

Results of PCA are given in Fig. 6a, b. For district Jhelum, variables loaded onto component 1 include the following: FC $(r=0.004)$, UV $(r=0.01)$, RI $(r=0.015)$, and FL $(r=0.999)$, while on component 2 they included the following: FC $(r=0.02)$, UV $(r=-0.038)$, RI $(r=0.998)$, and FL $(r=-0.015)$. For Lahore district, variables loading onto component 1 were FC $(r=0.0067)$, UV $(r=$ $0.011)$, RI $(r=0.016)$, and FL $(r=0.999)$ and component 2 were FC $(r=0.02)$, UV $(r=-0.021)$, RI $(r=0.999)$, and FL $(r=-0.017)$. The first two axes of the PCA showed 99.9\% variation in samples (component 1: 99.9\%; component 2: $0.1 \%$ ) from Jhelum (Fig. 6a) and 99.87\% variation in samples (component 1: 99.87\%; component 2: 0.119\%) from Lahore (Fig. 6b). Each principal component is not correlated with other principal components recorded from Jhelum and Lahore, respectively. Findings are resembled with reported study [78].

The statistical analysis shows that different groups are present in the cluster analysis, which are differentiated on the basis of values. The statistical analysis shows that two groups are present in the cluster analysis in Jhelum, i.e., group 1 (G1) and group 2 (G2). G1 and G2 have distance/variability of 45 points; G1 has species as LA, HCO, HCR, HJ, HS, RP, LPA, BS, and LTE (code are present in Table 2). G2 has two subgroups, i.e., subgroup 1 (SG1) and subgroup 2 (SG2) have 30 variability points. SG1 was further divided into two groups as SG1A and SG1B (variability = 14 points); SG2 was further divided into two groups as SG2A and SG2B (variability $=15$ points) (Fig. 7a, b).The statistical analysis shows that two groups are present in the cluster analysis in Lahore, i.e., group 1 (G1) and group 2 (G2). G1 and G2 have distance/variability of 54 points; G1 has species as ECS, HT, and LA (code are present in Table 2). G2 has two sub groups, i.e., subgroup 1 (SG1) and subgroup 2 (SG2) have 33 variability points. SG1 was further divided into two groups as SG1A and SG1B (variability = 14 points); SG2 was further divided into two groups as SG2A and SG2B (variability $=24$ points) (Fig. $7 \mathrm{a}, \mathrm{b}$ ). Findings are resembled with the reported study [78].

\section{Conclusion}

Traditional knowledge of local communities, particularly on the medicinal application of animal species to treat health disorders, indicates their strong association with the surrounding environment. Medicinal uses of herptiles and ichthyo fauna of Pakistan were studied for the first time. Furthermore, application of O. orientalis punjabiensis, F. francolinus, S. sarwari, C. punctate, O. aureus, C. idella, C. carpio, L. rohita, and C. auratus to cure various diseases in humans has rarely been reported before. Our findings provide baseline data that could be valuable in conservation and sustainable use of animal biodiversity in this region. Screening of pharmacological active substances and in vitro or in vivo assessment of biological activities of animal species with maximum FL, UV, RI, and RFM could be important for animal-based novel drugs.

\section{Acknowledgements \\ Local informants and the employees of Wildlife and Park, Fisheries and Aquaculture Departments of the Punjab Government are thankfully acknowledged. \\ Funding \\ We do not have any funding to conduct this survey. Therefore, waiver request was sent to the Editorial office, which agreed to grant a full waiver to this manuscript.}

\section{Availability of data and materials}

All data have already been included in the manuscript.

\section{Declaration}

Ethnomedicinal applications of animal species by the local communities of Punjab, Pakistan.

\section{Authors' contributions}

MA designed the study, conducted the field work, and prepared the first draft; $M U, A R A$, and NM were involved in the field survey and data collection; AA was involved in the data analysis; AMA contributed to the data analysis, interpolation, and final write up. All the authors critically read this article and approved as the final manuscript.

\section{Ethics approval and consent to participate}

The present study is purely based on the field survey instead of human or animal trials. Therefore, ethical approval and consent to participate is not applicable. However, formal consent was taken from informants regarding data collection and publication. In addition, ethical guidelines of the International Society of Ethnobiology (http://www.ethnobiology.net/) were strictly followed.

\section{Consent for publication}

Present paper does not contain any individual person's data; therefore, this section is not applicable to our study.

\section{Competing interests}

The authors declare that they have no competing interests.

\section{Publisher's Note}

Springer Nature remains neutral with regard to jurisdictional claims in published maps and institutional affiliations.

\section{Author details}

${ }^{1}$ Department of Zoology, Women University of Azad Jammu and Kashmir, Bagh, Pakistan. ${ }^{2}$ School of Agriculture and Biology, Shanghai Jiao Tong University, Shanghai, China. ${ }^{3}$ Statistical Wing, Department of Mathematics, Women University of Azad Jammu and Kashmir, Bagh, Pakistan. ${ }^{4}$ Department of Fisheries and Aquaculture, Punjab, Pakistan. ${ }^{5}$ Department of Environment Sciences, COMSATS University Islamabad, Abbottabad Campus, Abbottabad, Pakistan. 
Received: 24 May 2018 Accepted: 31 July 2018

\section{Published online: 15 August 2018}

\section{References}

1. Adeola MO. Importance of wild animals and their parts in the culture, religious festivals, and traditional medicine, of Nigeria. Environ Conserv. 1992;19:125-34.

2. Costa-Neto EM. Animal-based medicines: biological prospection and the sustainable use of zootherapeutic resources. An Acad Bras Cienc. 2005;77: $33-43$.

3. Zhang Z, Wang F. Effects of crude extract of earthworm on promoting blood circulation to removing stasis. Zhongguo Zhong xi yi jie he za zhi Zhongguo Zhongxiyi jiehe zazhi. Chinese J Integ Trad West Med. 1992;12: 741-3. 710

4. Alves RR, Rosa IL. Why study the use of animal products in traditional medicines? J Ethnobiol Ethnomed. 2005:1:1.

5. Unnikrishnan P. Animals in Ayurveda. Amruth Suppl. 1998;1:1-15.

6. Oudhia P. Traditional knowledge about medicinal insects, mites and spiders in Chhattisgarh, India. Insect Environ. 1995:4:57-8.

7. Beetz A, Uvnäs-Moberg K, Julius H, Kotrschal K. Psychosocial and psychophysiological effects of human-animal interactions: the possible role of oxytocin. Front Psychol. 2012;3(234):1-15.

8. Agosta WC, Bombardier beetles and fever trees: a close-up look at chemical warfare and signals in animals and plants. 1996.

9. Costa-Neto E, Marques J. Conhecimento ictiológico tradicional ea distribuição temporal e espacial de recursos pesqueiros pelos pescadores de Conde, Estado da Bahia, Brasil. Etnoecológica. 2000;4:56-68.

10. Dedeke G, Soewu D, Lawal O, Ola M. Pilot survey of ethnozoological utilisation of vertebrates in Southwestern Nigeria. Indilinga African J Indig Knowl Syst. 2006;5:87-96.

11. Yamakawa M. Insect antibacterial proteins. J Sericultural Sci Japan. 1998;67: 163-82.

12. Goodman WG. Chitin: a magic bullet. Food Insect News. 1989;2:6-7.

13. Kunin WE, Lawton JH. Does biodiversity matter? Evaluating the case for conserving species. Biodiversity: a biology of numbers and difference; 1996. p. 283-308.

14. Launet E. Dans les fôrets, à la recherche des médicaments de demain. Sci et Vie. 1993;904:86-91.

15. Bisset NG. One man's poison, another man's medicine? J Ethnopharmacol. 1991;32:71-81.

16. Daly JW. Ernest Guenther award in chemistry of natural products. Amphibian skin: a remarkable source of biologically active arthropod alkaloids. J Med Chem. 2003:46:445-52.

17. Clarke BT. The natural history of amphibian skin secretions, their normal functioning and potential medical applications. Biol Rev. 1997:72:365-79.

18. Pérez JM. Parasites, pests, and pets in a global world: new perspectives and challenges. J Exotic Pet Med. 2009;18(4):248-53.

19. Oliveira ES, Torres DF, Brooks SE, Alves RR. The medicinal animal markets in the metropolitan region of Natal City, Northeastern Brazil. J Ethnopharmacol. 2010;130:54-60.

20. Alves RR, Rosa IL, Neto NAL, Voeks R. Animals for the gods: magical and religious faunal use and trade in Brazil. Hum Ecol. 2012:40:751-80.

21. Alves RRN, Feijó A, Barboza RRD, Souto WMS, Fernandes-Ferreira $H$, Cordeiro-Estrela P, Langguth A. Game mammals of the Caatinga biome. Ethnobiol Conserv. 2016;5(5):1-51.

22. Alves RR. Relationships between fauna and people and the role of ethnozoology in animal conservation. Ethnobiol Conserv. 2012;1(2):1-69.

23. Ojango JMK, Okeyo AM, Philipsson J. Capacity building for sustainable use of animal genetic resources in developing countries. Appl. Animal Husb. Rural Develop. 2009;2:23-26.

24. Fabricant DS, Farnsworth NR. The value of plants used in traditional medicine for drug discovery. Environ Health Perspect. 2001;109:69.

25. Roberts TJ. The mammals of Pakistan. Revised ed. Karachi: Oxford University Press; 1997.

26. Mirza ZB, Wasiq H, A field guide to birds of Pakistan Bookland, Lahore: 2007.

27. Khan MS. Annotated checklist of amphibians and reptiles of Pakistan. Asi Herp Res. 2004;10:191-201.

28. Ali SS, Zoogeography palaeontology and wildlife management. 1998.Book.

29. GOP. Punjab development statistics. Lahore: Government of Punjab: Bureau of Statistics Government of the Punjab; 2011. p. 411.
30. Sheikh MS. District Pre-Investment Study - 2012, Jhelum. Lahore: Government of Punjab: Directorate of Industries, Punjab Poonch House; 2012.

31. Ahmed A. The culture of rural and urban areas of Pakistan. 2014 http://www.bitlanders.com/blogs/the-culture-of-rural-and-urban-areas-ofpakistan/97985.

32. Ahmad KS. Land use in the semi-arid zone of West Pakistan. Pakistan Geogr Rev. 1963;18:4-10.

33. Grimmett R, Inskipp C. \& Inskip T, Birds of the Indian subcontinent. Christopher Helm an imprint of A and C Black (Publisher) Ltd, 35 Bedford Row, London WCIR 4JH: 1998.

34. Ali Z, Shelly S, Bibi F, Joshua G, Khan A, Khan B, Akhtar M. Peculiarities of Mangla reservoir: biodiversity with sustainable use options. J Animal Plant Sci. 2011;21:372-80.

35. Sheikh MS. District Pre-Investment Study - 2012, Lahore. Lahore: Government of Punjab: Directorate of Industries, Punjab Poonch House; 2012.

36. Baloch AA. Urbanization of arable land in Lahore City in Pakistan: a casestudy. J Agric Biotechnol Sustain Devel. 2011:3:126.

37. Iqbal M, Saleem I, Ali Z, Khan M, Akhtar M. Bird ecology from the Ravi River of Lahore: habitat degradation. J Anim Plant Sci. 2011:21:817-21.

38. Maan MA, Chaudhry AA. Wildlife diversity in the Punjab (Pakistan). PJBS. 2001;1:417-20.

39. Close DA, Fitzpatrick MS, Li HW. The ecological and cultural importance of a species at risk of extinction. Pacific Lamprey Fisheries. 2002;27:19-25.

40. Joshua G, Ali Z. Avian diversity with the varying urban congestions of Lahore. J Anim Plant Sci. 2011;21:421-82.

41. Ali W, Javid A, Hussain SM, Azmat H, Jabeen G. The amphibians and reptiles collected from different habitat types in district Kasur, Punjab, Pakistan. Pakistan J Zool. 2016:48:1201-4.

42. Roberts TJ. Field guide to the large and medium-sized mammals of Pakistan. Karachi: Oxford University Press; 2005.

43. Roberts TJ. Field guide to the small mammals of Pakistan. Karachi: Oxford University Press; 2005

44. Roberts TJ. The birds of Pakistan. Vol. I. Karachi: Oxford University Press; 1991.

45. Roberts TJ. The birds of Pakistan. Vol. II. Karachi: Oxford University Press; 1992.

46. Khan MS. Amphibian and reptiles of Pakistan. Malabar: Krieger Publisher Company; 2006

47. Mirza MR. Fresh water fishes of Pakistan. Lahore: Urdu Science Board; 2004

48. Alexiades MN, Sheldon JW. Selected guidelines for ethnobotanical research: a field manual. New York: New York Botanical Garden; 1996.

49. Trotter RT, Logan MH. Informant consensus: a new approach for identifying potentially effective medicinal plants. In: Etkin NLE, editor. Plants in Indigenous Medicine and Diet, Biobehavioural Approaches. Bedford Hills: Redgrave Publishers; 1986. p. 91-112.

50. Phillips O, Gentry AH. The useful plants of Tambopata, Peru: I. Statistical hypotheses tests with a new quantitative technique. Econ Bot. 1993;47:15-32.

51. Hammer O, Harper DAT, Ryan PD. Past: Palaeontological statistical software package for education and data analysis. Palaeontol Electron. 2001;4:9.

52. Wilson L. Fats and oils for optimum health. The Center for Development 2015

53. Breteler MM. Vascular risk factors for Alzheimer's disease: An epidemiologic perspective. Neurobiol Aging. 2000;21:153-60.

54. Haag M. Essential fatty acids and the brain. Canadian J Psychiat. 2003;48. 195-203.

55. Hemme T, Otte J, Echeverri Perico R, Paarlberg R, Walker I, Pino H, Horton D, Polanía Vorenberg J, Toro Calderón J, López Balmaceda C, Status and prospects for smallholder milk production. A global perspective. FAO, Roma (Italia). 2010

56. Alabdulkarim B. Effect of camel milk on blood glucose, cholesterol, triglyceride and liver enzymes activities in female albino rats. World Appl Sci J. 2012;17:1394-7.

57. Sabahelkhier M, Faten M, Omer F. Comparative determination of biochemical constituents between animals (goat, sheep, cow and camel) milk with human milk. Res J Recent Sci. 2012;1:69-71.

58. Contarini G, Povolo M. Phospholipids in milk fat: composition, biological and technological significance, and analytical strategies. Int J Mol Sci. 2013;14:2808-31.

59. Vats $R$, Thomas $S$. A study on use of animals as traditional medicine by Sukuma tribe of Busega District in North-Western Tanzania. J Ethnobiol Ethnomed. 2015;11:1. 
60. Hall J, Textbook of medical physiology Elsevier: 2011.

61. Jia CS. Pangolin. Chinese Herb Med. 2013; http://chineseherbinfo.com

62. Zhou Z-M, Zhou Y, Newman C, Macdonald DW. Scaling up pangolin protection in China. Front Ecol Environ. 2014;12:97-8.

63. Lohani U. Eroding ethnozoological knowledge among Magars in Central Nepal. Ind J Trad Knowledge. 2011;10:466-73.

64. Lohani U. Traditional uses of animals among Jirels of Central Nepal. Ethno Med. 2011:5:115-24.

65. Al-Yousef N, Gaafar A, Al-Otaibi B, Al-Jammaz I, Al-Hussein K, Aboussekhra A. Camel urine components display anti-cancer properties in vitro. J Ethnopharmacol. 2012;143:819-25.

66. Alves RRN, Neta ROS, Trovão D, Barbosa J, Barros AT, Dias TLP. Traditional uses of medicinal animals in the semi-arid region of northeastern Brazil. J Ethnobiol Ethnomed. 2012;8:4269-8.

67. Barros FB, Varela SA, Pereira HM, Vicente L. Medicinal use of fauna by a traditional community in the Brazilian Amazonia. J Ethnobiol Ethnomed. 2012:8:37.

68. Kim H, Song M-J. Ethnozoological study of medicinal animals on Jeju Island, Korea. J Ethnopharmacol. 2013;146:75-82.

69. Kim $\mathrm{H}$, Song $\mathrm{M}-\mathrm{J}$. Analysis of ethnomedicinal practices for treating skin diseases in communities on Jeju Island (Korea). Ind J Trad Knowledge. 2014; 13:673-80

70. Melo R, Silva O, Souto A, Alves RRN, Schiel N. The role of mammals in local communities living in conservation areas in the northeast of Brazil: an ethnozoological approach. Trop Conserv Sci. 2014;7:423-39.

71. Mohanty I, Senapati MR, Jena D, Palai S. Diversified uses of cow urine. Int J Pharm Pharm Sci. 2014;6:20-2.

72. Al-Awadi A, Al-Judaibi A. Effects of heating and storage on the antifungal activity of camel urine. Clin Microbiol. 2015:3:1-6.

73. Vijayakumar S, Prabhu S, Yabesh JM, Prakashraj R. A quantitative ethnozoological study of traditionally used animals in Pachamalai hills of Tamil Nadu, India. J Ethnopharmacol. 2015;171:51.

74. Vijayakumar S, Yabesh JM, Prabhu S, Ayyanar M, Damodaran R. Ethnozoological study of animals used by traditional healers in Silent Valley of Kerala, India. J Ethnopharmacol. 2015;162:296-305.

75. Srithi K, Balslev H, Wangpakapattanawong P, Srisanga P, Trisonthi C. Medicinal plant knowledge and its erosion among the Mien (Yao) in northern Thailand. J Ethnopharmacol. 2009;123:335-42.

76. Bibi T, Ahmad M, Tareen RB, Tareen NM, Jabeen R, Rehman S-U, Sultana S, Zafar M, Yaseen G. Ethnobotany of medicinal plants in district Mastung of Balochistan province-Pakistan. J Ethnopharmacol. 2014;157:79-89.

77. Altaf M, Javid A, Umair M, labal KJ, Rasheed Z, Abbasi AM. Ethnomedicinal and cultural practices of mammals and birds in the vicinity of river Chenab, Punjab-Pakistan. J Ethnobiol Ethnomed. 2017;13:1-24.

78. Altaf M. Assessment of Avian and Mammalian Diversity at Selected Sites along river Chenab in Wildlife and Ecology. Lahore: University of Veterinary and Animal Sciences; 2016. p. 197.

79. Khan FM, Chaudhry H, Mustafa YS, Ahmad W, Farhan HM. Ethno-veterinary zoo-therapies and occult practices in greater Cholistan desert (Pakistan). Sci Int (Lahore). 2011;23:241-3.

80. Borah MP, Prasad SB. Ethnozoological study of animals based medicine used by traditional healers and indigenous inhabitants in the adjoining areas of gibbon wildlife sanctuary, Assam, India. J Ethnobiol Ethnomed. 2017:13:1-13.

81. Benarjee G, Srikanth K, Ramu G, Ramulua K. Ethnozoological study in a tropical wildlife sanctuary of Eturunagaram in the Warangal district, Andhra Pradesh. Ind J Trad Knowledge. 2010;9:701-4.

82. Bagde N, Jain S. An ethnozoological studies and medicinal values of vertebrate origin in the adjoining areas of Pench National Park of Chhindwara District of Madhya Pradesh, India. Int J life Sci. 2013;1:278-83.

83. Bagde N, Jain S. Study of traditional man-animal relationship in Chhindwara district of Madhya Pradesh, India. J Global Biosci. 2015;4:1456-63.

84. Mishra N, Rout S, Panda T. Ethno-zoological studies and medicinal values of similipal biosphere reserve, Orissa, India. Afr J Pharm Pharmacol. 2011;5:6-11.

85. Padmanabhan P, Sujana K. Animal products in traditional medicine from Attappady hills of western Ghats. Ind J Trad Knowledge. 2008;7:326-9.

86. Chakravorty J, Meyer-Rochow VB, Ghosh S. Vertebrates used for medicinal purposes by members of the Nyishi and Galo tribes in Arunachal Pradesh (North-East India). J Ethnobiol Ethnomed. 2011;7:1.
87. Lalmuanpuii J, Rosangkima G, Lamin H. Ethno-medicinal practices among the Mizo ethnic group in Lunglei district, Mizoram. Sci Vision. 2013;13:24-34.

88. Arshad M, Ahmad M, Ahmed E, Saboor A, Abbas A, Sadiq S. An ethnobiological study in Kala Chitta hills of Pothwar region, Pakistan: multinomial logit specification. J Ethnobiol Ethnomed. 2014;10:13.

89. Dixit A, Kadavul K, Rajalakshmi S, Shekhawat M. Ethno-medico-biological studies of South India. Ind J Trad Knowledge. 2010;9:116-8.

90. Lohani U. Man-animal relationships in Central Nepal. J Ethnobiol Ethnomed. 2010;6:1-11.

91. Chinlampianga M, Singh RK, Shukla AC. Ethnozoological diversity of Northeast India: empirical learning with traditional knowledge holders of Mizoram and Arunachal Pradesh. Ind J Trad Knowledge. 2013;12:18-30.

92. Galave $\mathrm{P}$, Jain A, Katewa S. Traditional veterinary medicines used by liestock owner of Rajhastan, India. Ind J Trad Knowledge. 2013;12:47-55.

93. Betlu ALS. Indigenous knowledge of zootherapeutic use among the Biate tribe of Dima Hasao District, Assam, Northeastern India. J Ethnobiol Ethnomed. 2013;9:1.

94. Aloufi A, Eid E. Zootherapy: a study from the northwestern region of the kingdom of Saudi Arabia and hashemite kingdom of Jordan. Ind J Trad Knowledge. 2016;15:561-9.

95. Chellappandian M, Pandikumar P, Mutheeswaran S, Paulraj MG, Prabakaran S, Duraipandiyan V, Ignacimuthu S, Al-Dhabi N. Documentation and quantitative analysis of local ethnozoological knowledge among traditional healers of Theni district, Tamil Nadu, India. J Ethnopharmacol. 2014;154:116-30.

96. Mootoosamy A, Mahomoodally MF. A quantitative ethnozoological assessment of traditionally used animal-based therapies in the tropical island of Mauritius. J Ethnopharmacol. 2014;154:847-57.

97. Paudyal R, Singh NB. Ethno-medicinal uses of animals and plants among the migratory tangbetons of Pokhara, Nepal. J Instr Sci Technol. 2014;19:145-9.

98. Jaroli D, Mahawar MM, Vyas N. An ethnozoological study in the adjoining areas of Mount Abu wildlife sanctuary, India. J Ethnobiol Ethnomed. 2010;6:6.

99. Belay M. Medicinal use of fauna in the indigenous medicine system of Gendewuha and Kumeraaftit Kebeles of Metema Woreda, North West Ethiopia. Int J Innov Res Devel. 2015:4:459-64.

100. Yirga G, Teferi M, Gebreslassea Y. Ethnozoological study of traditional medicinal animals used by the people of Kafta-Humera District, Northern Ethiopia. Int J Med Medical Sci. 2011;3:316-20.

101. Haileselasie TH. Traditional zootherapeutic studies in Degu'a Tembien, Northern Ethiopia. Curr Res J Biol Sci. 2012;4:563-9.

102. Alonso-Castro AJ, Carranza-Álvarez C, Maldonado-Miranda JJ, del Rosario J-SM, Quezada-Rivera DA, Lorenzo-Márquez H, Figueroa-Zúñiga LA, Fernández-Galicia C, Ríos-Reyes NA, de León-Rubio MÁ. Zootherapeutic practices in Aquismón, San Luis Potosí, México. J Ethnopharmacol. 2011; 138:233-7.

103. Martínez GJ. Use of fauna in the traditional medicine of native Toba (qom) from the Argentine Gran Chaco region: an ethnozoological and conservationist approach. Ethnobiol Conserv. 2013;2:1-43.

104. Ajagun EJ, Anyaku CE, Afolayan MP. A survey of the traditional medical and non-medical uses of animals species and parts of the indigenous. J Herb Med. 2017;5:26-32.

105. Patil MB, Shaikh M. Ethnozoological Study of Nandurbar District, Maharashtra State. Int I Sci Info. 2016;4:189-95.

106. Nascimento ALB, Lozano A, Melo J, Alves RRN, Albuquerqu UP. Functional aspects of the use of plants and animals in local medical systems and their implications forresilience. J Ethnopharmacol. 2016;194:348.

107. Dey A, Gorai P, Mukherjee A, Dhan R, Modak BK. Ethnobiological treatments of neurological conditions in the Chota Nagpur Plateau, India. J Ethnopharmacol. 2017;198:33-44.

108. Alves RR, Rosa IL. Zootherapy goes to town: the use of animal-based remedies in urban areas of NE and N Brazil. J Ethnopharmacol. 2007:113:541-55.

109. Alves RR, Rosa IL, Santana GG. The role of animal-derived remedies as complementary medicine in Brazil. Bioscience. 2007:57:949-55.

110. Yeshi K, Morisco $P$, Wangchuk $P$. Animal derived natural products used in the Bhutanese Sowa Riga medicine. J Ethnopharmacol. 2017; 207:192-202

111. Kulkarni B, Adwait D. Folk therapies of katkaries from Maharashtra. Ind J Trad Knowledge. 2011;10:554-8.

112. Soewu DA, Ayodele IA. Utilisation of Pangolin (Manis sps) in traditional Yorubic medicine in ljebu province, Ogun State, Nigeria. J Ethnobiol Ethnomed. 2009;5:39. 
113. Benítez G. Animals used for medicinal and magico-religious purposes in western Granada Province, Andalusia (Spain). J Ethnopharmacol. 2011;137: 1113-23.

114. Alves RR, Neto NAL, Brooks SE, Albuquerque UP. Commercialization of animal-derived remedies as complementary medicine in the semi-arid region of Northeastern Brazil. J Ethnopharmacol. 2009;124:600-8.

115. Alves RRN, Oliveira MGG, Barboza RRD, Lopez LCS, Oliveira MGG. An ethnozoological survey of medicinal animals commercialized in the markets of Campina Grande, NE Brazil. Human Ecol Rev. 2010;17:11-7.

116. Souto WMS, Barboza RRD, da Silva MJ, Alves RRN. Traditional knowledge of sertanejos about zootherapeutic practices used in ethnoveterinary medicine of NE Brazil. Ind J Trad Knowledge. 2012;11:259-65.

117. Jacobo-Salcedoa MR, Alonso-Castro AJ, Zarate-Martinez A. Folk medicinal use of fauna in Mapimi, Durango, México. J Ethnopharmacol. 2011;133:902-6.

118. Saikia K, Ahmed R. Wetland fish biodiversity of Majuli river island (India) and their medicinal values. The Clarion. 2012;2:81-86.

119. Teronpi V, Singh H, Tamuli A, Teron R. Ethnozoology of the Karbis of Assam, India: Use of ichthyofauna in traditional health-care practices. Anc Sci Life. 2012;32:99.

120. Mahawar MM, Jaroli D. Traditional zootherapeutic studies in India: a review. J Ethnobiol Ethnomed. 2008;4:17.

121. Deb AK, Emdad HC. 'Every mother is a mini-doctor': Ethnomedicinal uses of fish, shellfish and some other aquatic animals in Bangladesh. J Ethnopharmacol. 2011;134:259-67.

122. Muhammad N, Khan AM, Umair M, Qazi A, Yaqoob M, Ashraf S, Khan Q, Faroog M. Assessment of distribution and ethnocultural uses of the sol (Channa marulius) in Punjab, Pakistan. J Wildl Ecol. 2017;1:35-41.

123. Vallejo JR, González JA. Fish-based remedies in Spanish ethnomedicine: a review from a historical perspective. J Ethnobiol Ethnomed. 2014;10:37.

124. Muhammad N, Umair M, Khan AM, Abbasi AR, Khan Q, Khan A, Awan MZ. Assessment of the diversity and ethno-medicinal uses of the carps in Punjab, Pakistan. J Wildl Ecol. 2017;1:52-60.

125. Mawla F, Khatoon S, Rehana F, Jahan S, Shelley M, Hossain S, Haq WM Rahman S, Debnath K, Rahmatullah M. Ethnomedicinal plants of folk medicinal practitioners in four villages of Natore and Rajshahi districts, Bangladesh. Am Eur J Sustain Agric. 2012;6:406-16.

Ready to submit your research? Choose BMC and benefit from:

- fast, convenient online submission

- thorough peer review by experienced researchers in your field

- rapid publication on acceptance

- support for research data, including large and complex data types

- gold Open Access which fosters wider collaboration and increased citations

- maximum visibility for your research: over $100 \mathrm{M}$ website views per year

At $\mathrm{BMC}$, research is always in progress.

Learn more biomedcentral.com/submissions 